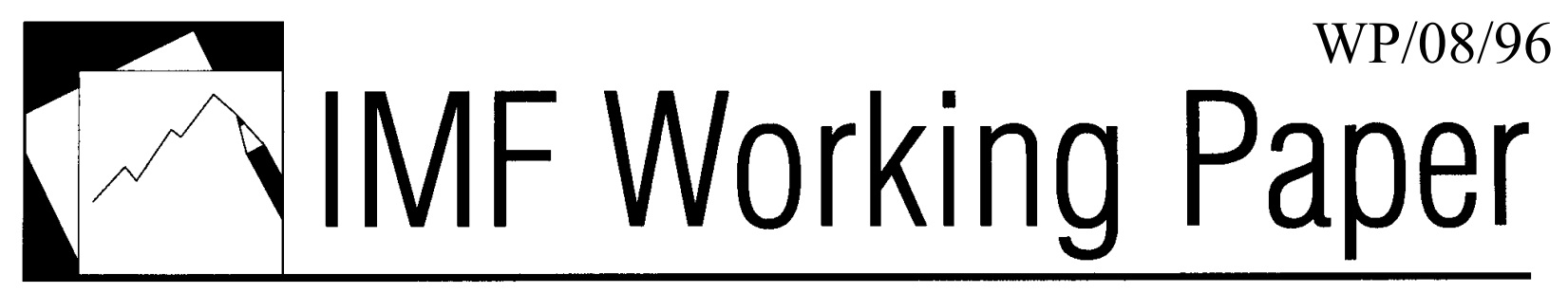

\title{
Accumulating Foreign Reserves Under Floating Exchange Rates
}

Fernando M. Gonçalves 



\title{
IMF Working Paper
}

Western Hemisphere Department

Accumulating Foreign Reserves Under Floating Exchange Rates

Prepared by Fernando M. Gonçalves ${ }^{1}$

Authorized for distribution by Tamim Bayoumi

April 2008

\begin{abstract}

\section{This Working Paper should not be reported as representing the views of the IMF.} The views expressed in this Working Paper are those of the author(s) and do not necessarily represent those of the IMF or IMF policy. Working Papers describe research in progress by the author(s) and are published to elicit comments and to further debate.
\end{abstract}

Official accumulation of foreign reserves may be perceived as interventions to influence the exchange rate, undermining the credibility of floating exchange rates and inflation targets. This paper develops a theoretical framework to study the interaction between reserve accumulation and monetary policy. The model uncovers a trade-off between the speed of reserve accumulation and anti-inflationary credibility. Under reasonable assumptions, delegation of intervention and monetary policy decisions to separate government agencies allows faster reserve accumulation, while centralization of these decisions results in a more stable economy. The analysis underscores the importance of rather overlooked institutional features of policymaking in open economies.

JEL Classification Numbers:E52, E58, F31, F41.

Keywords: Foreign Reserves, Official Intervention, Foreign Exchange Market, Floating Exchange Rate, Monetary Policy.

Author’s E-Mail Address: fgoncalves@imf.org

\footnotetext{
${ }^{1}$ I would like to thank Barry Eichengreen, Alejandro Gaytán, Jesús González, Richard Lyons, Maurice Obstfeld and seminar participants at Banco de Mexico and the 2006 LACEA meeting. This paper is based on a chapter of my dissertation. Remaining errors are mine.
} 


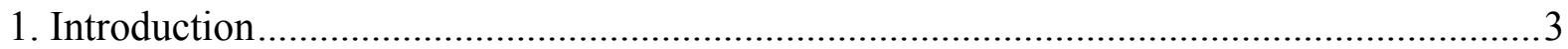

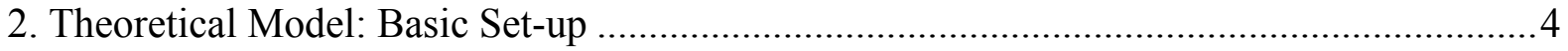

3. Complete Information......................................................................................... 7

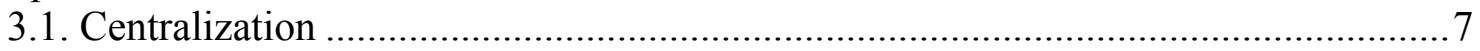

3.2. Institutional Arrangements in Practice .............................................................. 10

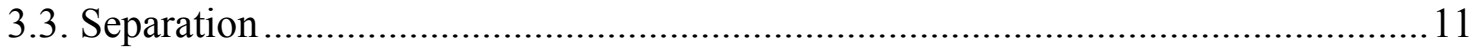

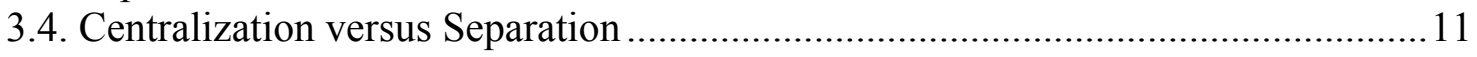

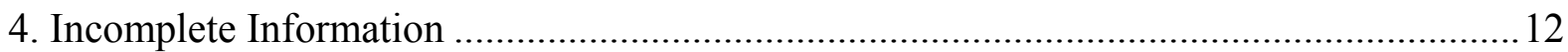

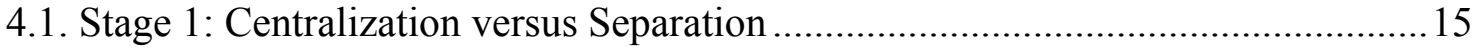

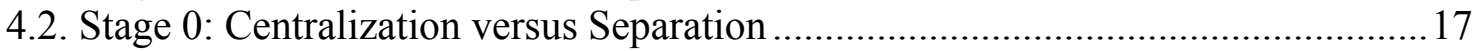

5. Comparative Analysis Under Incomplete Information............................................. 19

5.1. Simulation of Stage 0 Parameters.....................................................................20

5.2. The Trade-off Between Reserve Accumulation and Credibility Building..............23

5.3. Centralization versus Separation ...................................................................... 24

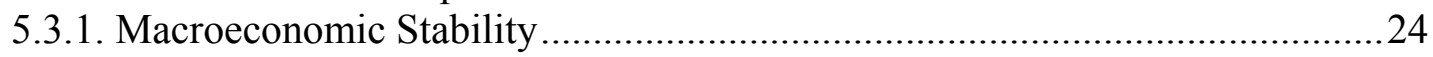

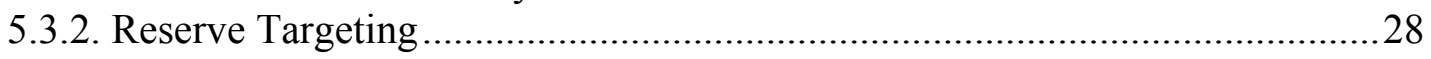

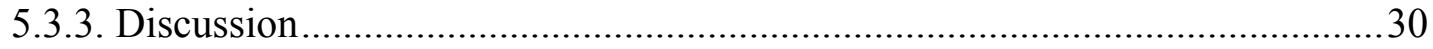

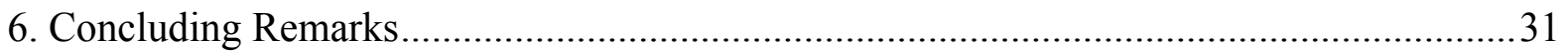

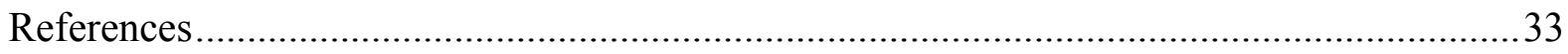

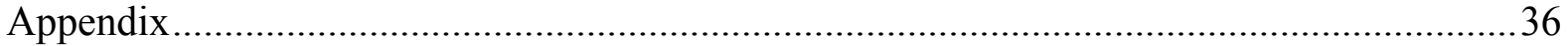

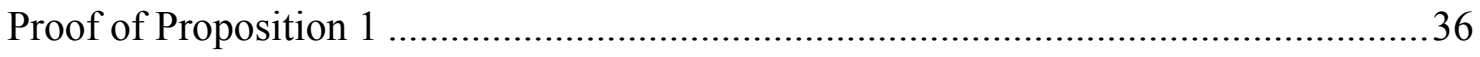

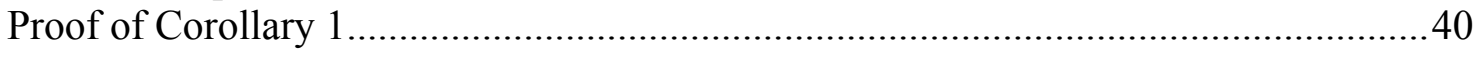

Figures

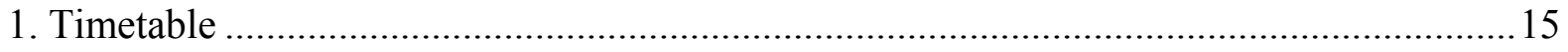

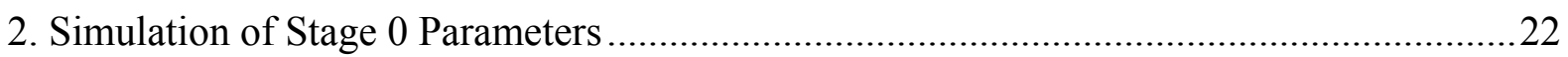

3. Macroeconomic Stability - Centralization versus Separation ........................................22

4. Reserve Targeting - Centralization versus Separation .................................................29 


\section{Introduction}

This paper investigates the interaction between monetary policy and accumulation of foreign reserves under floating exchange rates. Typically, in order to accumulate foreign reserves authorities have to acquire foreign currency in foreign exchange markets. However, if market participants interpret these acquisitions not as reserve accumulation but as interventions aimed at influencing the exchange rate, the credibility of other goals of monetary policy, such as price stability, may be undermined. To study this issue, a theoretical framework is developed in which official interventions (broadly defined as government transactions in the foreign exchange market) are implemented by policymakers that have the simultaneous goals of macroeconomic stabilization and reserve accumulation under floating exchange rates.

The model assumes interventions are always sterilized and takes into account the cost of intervention implied by monetary policy decisions. In traditional monetary models of exchange rate determination, sterilized interventions do not have any effect on equilibrium exchange or inflation rates, ${ }^{1}$ but this is not the case when the cost of intervening is internalized by authorities. In addition, when the monetary authority lacks credibility, economic agents are uncertain about monetary policy goals and try to infer them from the information content of official interventions. In other words, sterilized interventions are perceived as signals about future monetary policy decisions as in Mussa (1981) and may also influence equilibrium exchange and inflation rates through this expectations channel. The model is used to investigate alternative designs for the implementation of intervention policy and establishes a trade-off between faster reserve accumulation and monetary policy credibility.

The applicability of the analysis is broad and the results obtained might be relevant to many central banks that have been seeking to accumulate reserves and whose stated inflation objectives lack credibility. As reserve accumulation emerges as an important policy goal, it becomes crucial to understand how this goal interacts with other macroeconomic objectives, such as inflation and output stabilization, and the present paper is a first step in this direction.

\footnotetext{
${ }^{1}$ In such models, the nominal exchange rate in period $t, s_{t}$, is given by $s_{t}=\frac{1}{1+\eta} \sum_{j=t}^{\infty}\left(\frac{\eta}{1+\eta}\right)^{j-t} E\left(m_{j}\right)$, where $m_{j}$ is money supply in time $j$, and $\eta$ is the interest elasticity of real money demand. See Obstfeld and Rogoff (1998), p. 526. Since sterilized interventions do not affect money supply, they do not have any impact on the exchange rate in these models.
} 
The remainder of the paper is as follows. Section 2 outlines the main features of the theoretical model. Section 3 discusses the benchmark case in which the inflation target pursued by the monetary authority is common knowledge and credible. Section 4 studies the case of incomplete information, or lack of credibility, where price setters are skeptical about announcements of the inflation target and initially follow their own priors about the monetary authority's goal. In section 5 the model under incomplete information is simulated, showing that a faster pace of accumulation of reserves can only be achieved at the cost of a less stable economy. It also discusses under what conditions centralized or separated monetary and intervention decisions are desirable for the purposes of accumulating reserves and improving anti-inflationary credibility. In addition, it shows how this translates into a trade-off between reserve accumulation and macroeconomic stability. Section 6 presents concluding remarks.

\section{Theoretical Model: Basic Set-Up}

Mussa (1981) argues that official interventions in the foreign exchange market may signal future intentions about monetary policy. In fact, because a purchase (sale) of foreign exchange would represent a capital loss in case of a future monetary policy contraction (expansion), one should expect authorities to align their current intervention choices to their future monetary plans. Hence, the signalling content of interventions would provide one reason why sterilized intervention might be effective in affecting exchange rates. $^{2}$

This section outlines the basic set-up of a model that links monetary policy decisions and sterilized interventions through the impact the former has on the cost of pursuing the later, in a spirit similar to Mussa's conjecture. The model is related to that of Vitale (2003) which, however, follows a different set-up and does not consider the accumulation of foreign reserves as a policy objective.

\footnotetext{
${ }^{2}$ In the 1990s various papers have attempted to evaluate the relevance of this signalling mechanism and, in general, they provide some support to Mussa's conjecture, as sterilized intervention is often found to be related to some extent to monetary policy and seems to condition investors' expectations. See, for example, Dominguez and Frankel (1993a, 1993b), Lewis (1995), and Kaminsky and Lewis (1996). Besides the signalling channel, the literature on the effects of sterilized interventions has also explored the portfolio balance channel, which is based on the assumption of imperfect substitutability of domestic and foreign assets. Edison (1993) and Sarno and Taylor (2001) provide surveys on both channels.
} 
Suppose a two-country world composed by the domestic and the foreign economies. There are two stages, 0 and 1 . In stage 0 , the amount intervened $x_{0}$ is chosen (a positive $x_{0}$ means a purchase of foreign currency) and in stage 1 the monetary authority sets monetary policy in order to achieve an inflation rate of $\pi_{1}$. To avoid unnecessary complications related to the choice of instruments and transmission mechanisms, it is assumed that the monetary authority is able to set the inflation rate directly.

The choices of $x_{0}$ and $\pi_{1}$ are guided by macroeconomic and intervention goals. The macroeconomic goals are output and inflation stabilization and can be captured by the following objective function

$$
L^{M A}=\theta\left(y_{1}-\bar{y}\right)^{2}+\alpha\left(\pi_{1}-\bar{\pi}\right)^{2}
$$

where the output goal is $\bar{y}$ and $y_{1}$ is output in the end of stage 1 . Similarly, $\bar{\pi}$ represents the target for the inflation rate and $\pi_{1}$ is the inflation rate chosen by the monetary authority in stage 1 . The superscript $M A$ stands for "monetary authority," which is responsible for pursuing the macroeconomic goals.

It is beyond the scope of this paper to derive an optimal level of foreign reserves. ${ }^{3}$ Instead, it is simply assumed that authorities want to accumulate reserves to achieve an exogenous level (optimal or not) designated by $\bar{R}$. The initial level of reserves before the game starts is normalized to zero and $\bar{R}$ is assumed to be positive (hence, the government is attempting to accumulate foreign reserves). The reserve objective assigned to the intervention authority can be represented by the objective function

$$
L^{R}=\left(\bar{R}-x_{0}\right)^{2}
$$

where the superscript $R$ denotes "reserves." It is assumed that the only way the intervention authority can accumulate reserves is by buying foreign currency in the foreign exchange market.

Importantly, intervention $x_{0}$ is assumed to be fully sterilized. That is, in stage 0 , when the intervention authority buys (sells) the amount $x_{0}$ of foreign currency, it also sells (buys) domestic assets in order to keep constant the level of liquidity in the economy. It is only in stage 1 that the monetary authority resets the level of liquidity in order to

\footnotetext{
${ }^{3}$ See, for example, Jeanne and Ranciere (2006) and references therein.
} 
achieve the inflation rate $\pi_{1}$. And this is implemented in more conventional ways, via open market operations, and not through non-sterilized interventions in the foreign exchange market, which would have the inconvenience of affecting the level of foreign reserves.

As in Bhattacharya and Weller (1997) and Vitale (1999, 2003), the authority that is responsible for foreign exchange intervention is accountable for possible financial losses that its actions might bring about. This means that, in parallel to its assigned goal of managing the level of reserves, the intervention authority will also be concerned with the financial result of its operations in the foreign exchange market, and will take into account the costs of intervening, which are given by

$$
C=\left(s_{0}-s_{1}\right) x_{0}
$$

Equation (3) reflects the capital commitment or cost of intervention emphasized by Mussa (1981). ${ }^{4}$ If in stage 0 the intervention authority buys (sells) reserves and a nominal appreciation (depreciation) occurs, the intervention authority will incur a capital loss $(C>0)$. Alternatively, $C$ can be seen as an speculative motive to intervene: if the intervention authority buys (sells) foreign currency and this is followed by a nominal depreciation (appreciation), its intervention strategy yields profits.

As a result of the assumptions above, the intervention authority will attempt to minimize

$$
L^{I N T}=\gamma L^{R}+\beta C,
$$

where the superscript INT denotes "intervention authority" and $\gamma$ and $\beta$ are the weights attributed to reserve targeting and the cost of intervention respectively.

To complete the description of the economy equations relating the inflation rate to both output and the nominal exchange rate are needed. In the first case, a simple Lucas supply curve is assumed:

$$
y_{1}=b\left(\pi_{1}-\pi_{1}^{e}\right),
$$

where $\pi_{1}$ and $\pi_{1}^{e}$ are respectively the inflation rate and the expected inflation rate in stage 1 (potential output is normalized to zero). Price setters will attempt to minimize

\footnotetext{
${ }^{4}$ The rate of return on the foreign currency between stage 0 and stage 1 is $r=\left(S_{1}-S_{0}\right) / S_{0}$, where $S_{t}$ is the nominal exchange rate at period $t$. This expression can be rewritten as $S_{1} / S_{0}=1+r$. Taking $\operatorname{logs}, s_{1}-s_{0}=\log (1+r)$. For small $r$, the approximation $\log (1+r) \approx r$ is reasonable and the expression $\left(s_{0}-s_{1}\right) x_{0}$ is a good approximation of the cost of intervention.
} 
their prediction errors with respect to the inflation rate in period 1 so as to reduce their real losses due to price changes - they will use all the information available to them to minimize the expected value of the distance between $\pi_{1}$ and $\pi_{1}^{e},\left|\pi_{1}-\pi_{1}^{e}\right|$.

Relative purchasing power parity is assumed to hold. Without loss of generality, the inflation rate in the foreign country is assumed to be zero. This means that nominal exchange rate changes can be identified with price changes: ${ }^{5}$

$$
s_{1}-s_{0}=\pi_{1} .
$$

All the parameters in the equations above are non negative. The parameters $\theta, \alpha, \beta$ and $\gamma$ give the weights associated to each of the policy goals described above, while $b$ is the parameter that describes the sensitivity of output to inflation surprises, $\pi_{1}-\pi_{1}^{e}$.

\section{Complete Information}

This section focuses on the simple case in which there is common knowledge about the policymakers' targets and actions. In other words, all the parameters in the monetary and intervention authorities' objective functions (equations 1-3) as well as their choices for intervention and inflation are observed by price setters. Two cases are analyzed: (1) the monetary authority is responsible for intervention decisions; and (2) intervention decisions are delegated to a separate authority. This analysis will serve as a benchmark to the more complicated case of incomplete information about the inflation rate targeted by the monetary authority, which is pursued in the next section.

\subsection{Centralization}

Under centralization, monetary and intervention policies are set by the same policymaker. In other words, the monetary authority is not only responsible for monetary policy, but also for intervening in the foreign exchange market. In this case, its objective

\footnotetext{
${ }^{5}$ The purchasing power parity assumption implies that $\log S=\log P-\log P^{*}$, where $P$ and $P^{*}$ are the price levels in the domestic and foreign economy respectively. This equation and the definition $s_{i}=\log S_{i}$ can be used to obtain the expression: $s_{1}-s_{0}=\log \left(P_{1} / P_{0}\right)-\log \left(P_{1}^{*} / P_{0}^{*}\right)$. For small $\pi_{1}$ and $\pi_{1}^{*}, \log \left(P_{1} / P_{0}\right)=\pi_{1}$ and $\log \left(P_{1}^{*} / P_{0}^{*}\right)=\pi_{1}^{*}$ are good approximations. Finally, making the simplifying assumption that $\pi_{1}^{*}=0$ yields $s_{1}-s_{0}=\pi_{1}$.
} 
function is

$$
\begin{aligned}
L_{c} & =L_{c}^{M A}+L_{c}^{I N T} \\
& =\theta\left(y_{1}-\bar{y}\right)^{2}+\alpha\left(\pi_{1}-\bar{\pi}\right)^{2}+\gamma\left(\bar{R}-x_{0}\right)^{2}+\beta\left(s_{0}-s_{1}\right) x_{0}
\end{aligned}
$$

where the subscript $c$ stands for "centralization".

The two stage game between the monetary authority and price setters is solved by backward induction. In stage 1, after having set the intervention level in stage 0, the monetary authority chooses the inflation level. Hence, the minimization problem that it solves in stage 1 is the following.

$$
\begin{aligned}
& \operatorname{Min}_{\pi_{1}} \theta\left(y_{1}-\bar{y}\right)^{2}+\alpha\left(\pi_{1}-\bar{\pi}\right)^{2}+\gamma\left(\bar{R}-x_{0}\right)^{2}+\beta\left(s_{0}-s_{1}\right) x_{0} \\
& \text { s.t. }\left\{\begin{array}{c}
y_{1}=b\left(\pi_{1}-\pi_{1}^{e}\right) \\
s_{1}-s_{0}=\pi_{1} \\
x_{0} \text { given }
\end{array}\right.
\end{aligned}
$$

The first order condition of this problem yields the following expression for $\pi_{1}$ :

$$
\pi_{1}=\bar{\pi}+\frac{b^{2} \theta}{\alpha+b^{2} \theta}\left(\pi_{1}^{e}-\bar{\pi}\right)+\frac{b \theta}{\alpha+b^{2} \theta} \bar{y}+\frac{\beta}{2\left(\alpha+b^{2} \theta\right)} x_{0} .
$$

Assuming price setters have rational expectations, the above expression can be simplified to

$$
\pi_{1}=\pi_{1}^{e}=\bar{\pi}+\frac{b \theta}{\alpha} \bar{y}+\frac{\beta}{2 \alpha} x_{0}
$$

Expressions (5) and (6) show that, due to the existence of costs to intervene $(\beta>0)$, the intervention level $x_{0}$ influences the inflation rate chosen by the monetary authority. If the monetary authority did not internalize the costs of intervening $(\beta=0)$, the equilibrium inflation rate would be identical to the conventional Barro and Gordon (1983) model: $\pi_{1}=\pi_{1}^{e}=\bar{\pi}+\frac{b \theta}{\alpha} \bar{y}$. In this case, it is easy to see that the monetary authority would simply intervene the amount necessary to achieve the desirable level of reserves: $x_{0}=\bar{R}$. Nonetheless, when the monetary authority places a positive weight in the cost of intervention $(\beta>0)$, there will be a trade-off between its macroeconomic goals and reserve accumulation.

In stage 0 , the monetary authority chooses $x_{0}$ taking as given the expression for $\pi_{1}$ 
above. The first order condition in stage 0 yields

$$
x_{0}=\frac{4 \alpha \gamma}{4 \alpha \gamma-\beta^{2}} \bar{R}+\frac{2 \alpha \beta}{4 \alpha \gamma-\beta^{2}} \bar{\pi} .
$$

Substituting the expression for $x_{0}$ above into equation (6), results in the following expression for inflation and expected inflation

$$
\pi_{1}=\pi_{1}^{e}=\frac{4 \alpha \gamma}{4 \alpha \gamma-\beta^{2}} \bar{\pi}+\frac{b \theta}{\alpha} \bar{y}+\frac{2 \beta \gamma}{4 \alpha \gamma-\beta^{2}} \bar{R}
$$

The signs of the coefficients of $\bar{\pi}, \bar{y}$, and $\bar{R}$ in expressions (7) and (8) depend on the sign of $4 \alpha \gamma-\beta^{2}$. Because the second order condition of the problem requires that $4 \alpha \gamma-\beta^{2}>0$, all coefficients are positive. ${ }^{6}$ This means that both $x_{0}$ and $\pi_{1}$ will be increasing in the inflation target, $\bar{\pi}$, and in the foreign reserves target, $\bar{R}$. Furthermore, inflation will also be increasing in the output target, $\bar{y}$, as typically obtained in the inflation bias literature. ${ }^{7}$

Does the second order condition $4 \alpha \gamma-\beta^{2}>0$ make economic sense? As argued by Vitale (2003), while the government authorities can not sustain the political burden of infinite losses (implying that $\beta$ has to be strictly greater than zero), the value taken by $\beta$ might well be very small, meaning that monetary authority's interventions are not mainly triggered off by speculative motives. In fact, this is in accordance with recent evidence from a survey conducted by Neely (2001), in which none of the central banks that responded agreed with the statement that profit from speculative trades is a main determinant of intervention decisions. At the same time, there is widespread anecdotal evidence that the weights placed in the goal of inflation stabilization $(\alpha)$ has become larger

\footnotetext{
${ }^{6}$ If $\gamma=0$, the first order condition with respect to $x_{0}$ yields $x_{0}=-\frac{2 \alpha}{\beta} \bar{\pi}$, implying an inflation rate of $\pi_{1}=\frac{b \theta}{\alpha} \bar{y}$. Since this inflation rate is smaller than $\bar{\pi}+\frac{b \theta}{\alpha} \bar{y}$, which is the inflation rate that would prevail if there were no interventions, it is tempting to interpret this results as if the authority was selling foreign exchange to bolster its anti-inflationary credibility. In fact, because a large inflation rate would imply capital losses to the monetary authority, interventions can potentially be used as a partial commitment mechanism against high inflation expectations. This idea has been explored by Eggertsson (2003) in a deflationary context. Nonetheless, since the second order condition is not satisfied when $\gamma=0$, the point $x_{0}=-\frac{2 \alpha}{\beta} \bar{\pi}$ and $\pi_{1}=\frac{b \theta}{\alpha} \bar{y}$ is actually a saddle point, not a point of minimum, and the intuition of Eggertsson's work does not apply in this model. This is because the capital loss $\beta\left(s_{0}-s_{1}\right) x_{0}$ is a concave function of $x_{0}$ and outweighs the convexity of $\alpha\left(\pi_{1}-\bar{\pi}\right)^{2}$ with respect to $x_{0}$ (this convexity is what would generate the idea explored by Eggertsson).

${ }^{7}$ Note from equations (7) and (8) that if $\beta=0$, then $\pi_{1}=\pi_{1}^{e}=\bar{\pi}+\frac{b \theta}{\alpha} \bar{y}$ and $x_{0}=\bar{R}$, as argued before.
} 
in recent years for most central banks in the world. Similarly, reserve level management has grown in relevance for many central banks, as is evident by the great emphasis placed by the recent literature in issues such as the optimal level of foreign reserves. Hence, it seems reasonable to assume that the second order condition $4 \alpha \gamma-\beta^{2}>0$ makes economic sense and, throughout the paper, it is assumed to hold.

\subsection{Institutional Arrangements in Practice}

As shown above, when monetary policy and intervention decisions are delegated to the same agent, interventions affect the equilibrium level of inflation. But this result clearly hinges on the specific institutional arrangement of centralized decisions. In reality, this is only one of the institutional alternatives available to policymakers and different arrangements exist in practice.

Vitale (2003) discusses a variety of institutional designs adopted by industrial countries. A great diversity of institutional arrangements is also observed in emerging market economies, as described in Moser-Boehm (2005). In some countries the central bank has full jurisdiction over foreign exchange intervention and use its own funds to finance its costs (centralization case). In others, interventions are an initiative of the Treasury and the central bank may or may not be consulted, and may or may not act as an agent. Systems of shared responsibility also exist and the cost of intervening is sometimes split between the monetary authority and the Treasury. Finally, in some cases intervention decisions are fully separated from monetary policy decisions, meaning that they are delegated to an authority other than the monetary authority. Transitions also occurred between a framework in which decisions were separated to one in which they were centralized and vice-versa. ${ }^{8}$

To gain some perspective on how different choices of institutional arrangements may matter for policy outcome, the following section contrasts the case of centralization developed above with the case in which the two decisions are implemented by separate government agencies. Vitale (2003) performed the same comparison without incorporating accumulation of reserves as a policy objective.

\footnotetext{
${ }^{8}$ See, for instance, Schwartsman (2004) for the case of Brazil.
} 


\subsection{Separation}

Under separation, intervention policy is delegated to some governmental agency other than the monetary authority (typically the Treasury). In this case, the monetary authority will only be concerned with macroeconomic goals, and will set monetary policy to minimize

$$
L_{s}^{M A}=\theta\left(y_{1}-\bar{y}\right)^{2}+\alpha\left(\pi_{1}-\bar{\pi}\right)^{2},
$$

where the subscript $s$ stands for "separation." The designated intervention authority chooses the size of intervention taking into account not only its assigned reserve targeting goal, but also the costs of intervening:

$$
L_{s}^{I N T}=\gamma\left(\bar{R}-x_{0}\right)^{2}+\beta\left(s_{0}-s_{1}\right) x_{0} .
$$

The problem of the monetary authority in stage 1 is to minimize $L_{s}^{M A}$ subject to $y_{1}=b\left(\pi_{1}-\pi_{1}^{e}\right)$, which yields

$$
\pi_{1}=\bar{\pi}+\frac{b^{2} \theta}{\alpha+b^{2} \theta}\left(\pi_{1}^{e}-\bar{\pi}\right)+\frac{b \theta}{\alpha+b^{2} \theta} \bar{y} .
$$

Assuming rational expectations, the above expression is simplified to

$$
\pi_{1}=\pi_{1}^{e}=\bar{\pi}+\frac{b \theta}{\alpha} \bar{y} .
$$

In stage 0 , the intervention authority chooses the intervention level to minimize $L_{s}^{I N T}$ subject to $s_{1}-s_{0}=\pi_{1}$ and $\pi_{1}=\bar{\pi}+\frac{b \theta}{\alpha} \bar{y}$, resulting in

$$
x_{0}=\bar{R}+\frac{\beta}{2 \gamma} \bar{\pi}+\frac{b \theta \beta}{2 \alpha \gamma} \bar{y} .
$$

\subsection{Centralization versus Separation}

The results show that both the choice of intervention level, $x_{0}$, and inflation rate, $\pi_{1}$, are affected by the institutional structure of decision making. In particular, the inflation rate in the case of separation is smaller (bigger) than in the case of centralization if intervention is positive (negative). Assuming that authorities have the desire to accumulate reserves $(\bar{R}>0)$ and given the second order condition of the problem $\left(4 \alpha \gamma-\beta^{2}>0\right)$, equations (7) and (11) imply that the intervention level $x_{0}$ will be positive with certainty, 
so that the inflation level under separation is lower than under centralization.

In terms of macroeconomic stabilization, separation is indeed a superior arrangement, as shown by the following expression:

$$
L_{c}^{M A}-L_{s}^{M A}=\frac{\beta[\beta \bar{\pi}+2 \gamma \bar{R}]\left\{\alpha \beta[\beta \bar{\pi}+2 \gamma \bar{R}]+2 b \theta \bar{y}\left(4 \alpha \gamma-\beta^{2}\right)\right\}}{\left(4 \alpha \gamma-\beta^{2}\right)^{2}} .
$$

Because $4 \alpha \gamma-\beta^{2}>0$, the expression above is positive for positive $\bar{R}$. This is not a surprising result. In fact, in the separation case the monetary authority does not internalize the costs of intervention and, in practice, acts as if it was facing a zero intervention cost $(\beta=0)$. This implies that monetary and intervention policy decisions will be independent and monetary policy will be set aiming solely at macroeconomic stabilization. As expected, this leads to the choice of a better trade-off between output and inflation stabilization.

A similar comparison between the results of intervention policy under centralization and under separation yields $L_{c}^{I N T}-L_{s}^{I N T}>0$. This result is also not surprising; it is a simple consequence of the fact that, under separation, intervention authorities can choose the intervention level without taking into consideration the consequences of this choice to inflation, achieving a better trade-off between its goals of reserve targeting and cost minimization.

The comparison between centralization and separation does not yield a clear-cut result when intervention decisions are evaluated solely in terms of reserve targeting (that is, without considering the term that captures cost minimization, $\left.\beta\left(s_{0}-s_{1}\right) x_{0}\right)$. In other words, equally plausible parameter values yield different results in terms of whether separation or centralization is a better arrangement to pursue the goal of accumulating reserves. This implies that, under complete information, it is not possible to conclude that separation is a superior arrangement relative to centralization in terms of both macroeconomic stability and reserve accumulation.

\section{Incomplete Information}

There are various forms of asymmetric information that can arise between policymakers and private agents. A strategy commonly used in the monetary policy literature 
to capture these asymmetries is to assume incomplete information about policymakers' preferences. This can be done by incorporating uncertainty about the policymaker's type ${ }^{9}$ (for instance, about how strong its commitment to fight inflation is) or by assuming that private agents are unable to observe the precise targets pursued by the policymaker. We follow Stein (1989) and Vitale (2003) in assuming that there is incomplete information about monetary authority's nominal target, which in our model is the target for inflation rate, $\bar{\pi} \cdot{ }^{10}$

Before proceeding, it is useful to discuss why in general policymakers' announcement about their policy goals lack credibility and why it is often difficult for them to manipulate price setters' beliefs. This will justify the interpretation of the incomplete information case as one in which monetary authority's announcements lack credibility.

Suppose the monetary authority makes an announcement about its target for inflation, $\bar{\pi}$, and that price setters believe this announcement. This is equivalent to assuming that the monetary authority can freely set the expected value of the target level, $\bar{\pi}^{e}$. If this is the case, it can announce the true target, $\bar{\pi}$, and this would be the complete information case. However, it can also act strategically and announce a target level that minimizes its objective function. For example, in the simple case in which the monetary authority's objective is to minimize $L^{M A}=\theta\left(y_{1}-\bar{y}\right)^{2}+\alpha\left(\pi_{1}-\bar{\pi}\right)^{2}$ subject to $y_{1}=b\left(\pi_{1}-\pi_{1}^{e}\right)$, it would be optimal to announce a target equal to $\bar{\pi}-\frac{\alpha+b^{2} \theta}{b \alpha} \bar{y}$. Price setters would set $\pi_{1}^{e}=\bar{\pi}-\bar{y} / b$ and the monetary authority would then be able to set $\pi_{1}=\bar{\pi}$, attaining a value of zero for their objective function.

Because, as in the example above, the monetary authority is able and willing to deviate from the announcement, price setters will generally not believe in authority's announcements about the inflation target. Instead, they may use their own priors about the target, which might be based, for example, on the historical behavior of the monetary authority. This implies in particular that, for authorities that have "misbehaved" in the past but that are now truly committed to reducing inflation, price setters might have a prior for the inflation target that is larger than the actual one.

As in the complete information case, two institutional designs are analyzed: centralization and separation of monetary and intervention decisions. However, it is now

\footnotetext{
${ }^{9}$ Backus and Driffil (1985) and Barro (1986) are early examples of models of this kind.

${ }^{10}$ In Stein (1989) and Vitale (2003) the monetary authority pursues a target for nominal exchange rate.
} 
assumed that price setters do not observe $\bar{\pi}$ but, instead, have a prior about its distribution. In particular, it is assumed that in the beginning of stage 0 price setters believe that the inflation targeted by the monetary authority is normally distributed with mean $\bar{\pi}_{0}^{e}$ and variance $\Sigma_{0}^{\pi}$. Therefore, price setters' best prediction about the inflation target before the game starts is simply $\bar{\pi}_{0}^{e}$.

Price-setters (which are also dealers in the foreign exchange market) cannot observe the actual value intervened, $x_{0}$. Instead, they observe a noisy signal $x_{0}+\mu_{0}$, where $\mu_{0}$ is normally distributed with mean 0 and variance $\sigma^{2}$. The noisy term $\mu_{0}$ can be regarded as a measure of the lack of transparency of foreign exchange interventions and its variance $\sigma^{2}$ as a measure of the degree of opaqueness of that market. ${ }^{11}$ This opaqueness might originate from deliberate attempts by the government to exploit the fragmented structure of foreign exchange markets in order to obscure the actual size of official interventions. However, as shown below, even when the government publicly declares the amount intervened these announcements are not credible, and market participants still focus on the total market orders, $x_{0}+\mu_{0}$, to infer the actual level of official intervention.

After $\bar{\pi}_{0}^{e}$ is set in the beginning of stage 0, the monetary authority (in the case of centralization) or other designated authority (in the case of separation) will set the intervention policy. Price setters will then use the new information available (the signal about interventions) to update expectations about the inflation rate target and the intervention level itself. In stage 1 , the monetary authority will set the inflation rate $\pi_{1}$. This timetable for the game between price setters and policymakers is summarized in the diagram below.

\footnotetext{
${ }^{11}$ Vitale (1999) was the first to characterize foreign exchange intervention this way. See his paper for a more extensive discussion of this analytical framework.
} 
Figure 1. Timetable

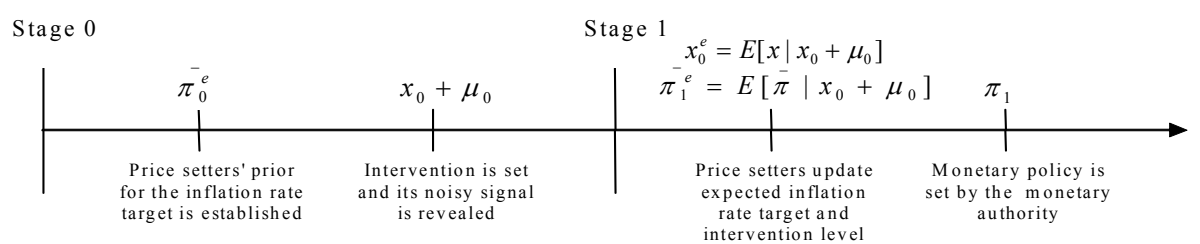

The solution is obtained by backward induction. For comparison purposes stage 1 is first analyzed for both the centralization and the separation cases. Then, the same is done for stage 0 . This permits highlighting the differences and similarities between the two cases in each stage.

\subsection{Stage 1: Centralization versus Separation}

In the case of centralized decisions of monetary and intervention policies, the monetary authority solves the following problem in stage 1 .

$$
\begin{aligned}
& \operatorname{Min}_{\pi_{1}} \theta\left(y_{1}-\bar{y}\right)^{2}+\alpha\left(\pi_{1}-\bar{\pi}\right)^{2}+\gamma\left(\bar{R}-x_{0}\right)^{2}+\beta\left(s_{0}-s_{1}\right) x_{0} \\
& \text { s.t. }\left\{\begin{array}{c}
\pi_{1}^{e}=\bar{\pi}_{1}^{e}+\frac{b \theta}{\alpha} \bar{y}+\frac{\beta}{2 \alpha} x_{0}^{e} \\
y_{1}=b\left(\pi_{1}-\pi_{1}^{e}\right) \\
s_{1}-s_{0}=\pi_{1} \\
x_{0} \text { given }
\end{array}\right.
\end{aligned}
$$

The only difference between this problem and the one solved in the complete information case is that now the monetary authority faces an extra constraint: $\pi_{1}^{e}=$ $\bar{\pi}_{1}^{e}+\frac{b \theta}{\alpha} \bar{y}+\frac{\beta}{2 \alpha} x_{0}^{e}$. This constraint is analogous to equation (6), derived for the complete information case, but now price setters are skeptical about the announced values of the actual inflation rate targeted by the policymaker, $\bar{\pi}$, and the intervention set in stage $0, x_{0}$. They use instead their expectations for both variables, $\bar{\pi}_{1}^{e}$ and $x_{0}^{e}$, to form their expectations about inflation rate in stage $1, \pi_{1}^{e}$. The analysis of stage 0 below will show 
how $\bar{\pi}_{1}^{e}$ and $x_{0}^{e}$ are determined and how they relate to the prior for the inflation rate target, $\bar{\pi}_{0}^{e}$, and to the intervention signal, $x_{0}+\mu_{0}$. But in stage 1 these values have already been set and can be taken as given.

The first order condition for the minimization problem above yields:

$$
\pi_{1}=\bar{\pi}+\frac{b \theta}{\alpha} \bar{y}+\frac{\beta}{2 \alpha} x_{0}+\frac{b^{2} \theta}{\alpha+b^{2} \theta}\left[\left(\bar{\pi}_{1}^{e}-\bar{\pi}\right)+\frac{\beta}{2 \alpha}\left(x_{0}^{e}-x_{0}\right)\right] .
$$

Equation (12) illustrates the two channels of influence that interventions have on monetary policy in the case of centralized decisions. First, there is a cost-of-intervention channel (following the terminology in Vitale, 2003) represented by the terms $\frac{\beta}{2 \alpha} x_{0}$ and $\frac{b^{2} \theta}{\alpha+b^{2} \theta} \frac{\beta}{2 \alpha}\left(x_{0}^{e}-x_{0}\right)$. When the monetary authority sets the inflation rate in period $1, \pi_{1}$, it also determines the exchange rate in that period, $s_{1}$, which affects the cost of intervening, $\beta\left(s_{0}-s_{1}\right) x_{0}$. The existence of such cost affects the choice of the monetary authority. The first term, $\frac{\beta}{2 \alpha} x_{0}$, is also present in the complete information case (see equation (6)). The second term arises only when there is incomplete information and is a function of the unexpected component of intervention, $x_{0}^{e}-x_{0}$. As in the complete information case, if the policymaker does not internalize the cost of intervention (i.e., if $\beta=0$ ), both terms become null and the cost-of-intervention channel vanishes.

The second channel is related to the effect of interventions on the expected inflation rate target, $\bar{\pi}_{1}^{e}$, and is called the expectations channel. Because the intervention signal, $x_{0}+\mu_{0}$, contains information about the actual target for inflation, it is used by price setters to update their initial prior about the target. The expectations channel is present even when costs of intervention are not internalized by the monetary authority.

When monetary and intervention policy decisions are separated, the monetary authority solves the same problem as above, except that now $\pi_{1}^{e}=\bar{\pi}_{1}^{e}+\frac{b \theta}{\alpha} \bar{y}$ and the objective function has a simpler form: $L_{s}^{M A}=\theta\left(y_{1}-\bar{y}\right)^{2}+\alpha\left(\pi_{1}-\bar{\pi}\right)^{2}$. In this case, the first order condition yields

$$
\pi_{1}=\bar{\pi}+\frac{b \theta}{\alpha} \bar{y}+\frac{b^{2} \theta}{\alpha+b^{2} \theta}\left(\bar{\pi}_{1}^{e}-\bar{\pi}\right) .
$$

As expected, the cost-of-intervention channel disappears since intervention costs are no longer internalized by the monetary authority. However, differently from the complete information case, the separation of intervention decisions is no longer sufficient to 
fully isolate inflation from intervention decisions because the expectations channel is still present. This result relies on the assumption that the intervention authority has the same information set as the monetary authority and, in particular, is able to observe the monetary authority's inflation target-or at least can discern it more precisely than the public. This is a realistic assumption in the many countries where the government establishes policy goals and delegates policy implementation (e.g., countries with operationally independent central banks). ${ }^{12}$

\subsection{Stage 0: Centralization versus Separation}

In stage 0 , price setters rationally use the information contained in the intervention signal, $x_{0}+\mu_{0}$, to update their beliefs about the the actual inflation rate targeted by the policymaker, $\bar{\pi}$. The following proposition, which is demonstrated in the appendix, holds.

Proposition 1 Under both centralization and separation, the intervention policy implemented by the designated authority has the form

$$
x_{0}=m_{i} \bar{\pi}_{0}^{e}+n_{i} \bar{R}+p_{i}\left(\bar{\pi}-\bar{\pi}_{0}^{e}\right)+q_{i} \bar{y}
$$

and the price setters' expected values for the inflation rate targeted by the monetary authority in stage $1, \bar{\pi}_{1}^{e}$, and for the intervention policy implemented in stage $0, x_{0 i}^{e}$, are given by

$$
\begin{gathered}
\bar{\pi}_{1 i}^{e}=\bar{\pi}_{0}^{e}+\lambda_{i}\left(x_{0}+\mu_{0}-m_{i} \bar{\pi}_{0}^{e}-n_{i} \bar{R}-q_{i} \bar{y}\right), \\
x_{0 i}^{e}=m_{i} \bar{\pi}_{0}^{e}+n_{i} \bar{R}+q_{i} \bar{y}+\lambda_{i}\left(x_{0}+\mu_{0}-m_{i} \bar{\pi}_{0}^{e}-n_{i} \bar{R}-q_{i} \bar{y}\right),
\end{gathered}
$$

where $i=c, s\left(c=\right.$ centralization case, and $s=$ separation case) and $m_{i}, n_{i}, p_{i}, q_{i}, \lambda_{i}$ are coefficients given in the appendix.

\footnotetext{
${ }^{12}$ If the central bank also has goal independence (i.e., it sets the objectives of monetary policy), the intervention authority may not have any private information about monetary policy targets. Assuming that the intervention authority's information set is the same as the public's, it is easy to show that it would choose $x_{0}=\bar{R}+\frac{\beta}{2 \gamma} \bar{\pi}_{0}^{e}+\frac{b \theta \beta}{2 \alpha \gamma} \bar{y}$ and, based on this expression, the monetary authority would set the inflation rate to $\pi_{1}=\bar{\pi}+\frac{b \theta}{\alpha} \bar{y}+\frac{b^{2} \theta}{\alpha+b^{2} \theta}\left(\bar{\pi}_{0}^{e}-\bar{\pi}\right)$. In this case, there would be no learning by the public or by the intervention authority about the true inflation target and, as a consequence, the monetary authority would not be able to build an anti-inflationary credibility through foreign exchange interventions.
} 
Proposition 1 establishes important results. First, centralization and separation yield the same functional form for the amount intervened, $x_{0}$. Relative to the complete information case there are now two new factors determining interventions. The term $p_{i}\left(\bar{\pi}-\bar{\pi}_{0}^{e}\right)$ shows how lack of credibility about the inflation target affects intervention policies both under centralization and separation. In the case in which the monetary authority is initially perceived to be more inflationary than in reality $\left(\bar{\pi}<\bar{\pi}_{0}^{e}\right)$, the term $p_{i}\left(\bar{\pi}-\bar{\pi}_{0}^{e}\right)$ is negative meaning that, ceteris paribus, less intervention will take place and, consequently, less reserves will be accumulated. Hence, for authorities that are in a credibility building stage, the goal of accumulating reserves might be undermined even when intervention policy is delegated to a separate authority. The last term in equation (14) shows that interventions are also a function of the output target, $\bar{y}$, as this also affects the cost of intervening through its impact on inflation.

Equation (14) also makes clear that if authorities could credibly announce the level intervened in stage $0, x_{0}$, price setters would be able to infer the targeted level of inflation, $\bar{\pi}$. This is because, in equilibrium, $x_{0}$ is a simple function of $\bar{\pi}$. In other words, the proposition shows that, since credible announcements about the actual inflation rate target can be ruled out (as shown earlier), credible announcements about intervention policy can also be ruled out. Therefore, in the model, interventions need not be publicly announced and, even if they are, the announcements are not credible.

The proposition also shows that the intervention level $x_{0}$ has a direct impact on price setters' expectations about both the targeted inflation rate and the intervention level itself-the larger is $x_{0}$, the larger will be $\bar{\pi}_{1 i}^{e}$ and $x_{0 i}^{e}$. In particular, because the monetary policy set in stage 1 depends on $\bar{\pi}_{1}^{e}$ (equations (12) and (13)), official interventions can still influence monetary policy via an expectations channel, even when the costs of intervening are not internalized by the monetary authority.

Equations (15) and (16) can also be rewritten with the help of (14):

$$
\begin{gathered}
\bar{\pi}_{1 i}^{e}=\bar{\pi}_{0}^{e}+\lambda_{i}\left[p_{i}\left(\bar{\pi}-\bar{\pi}_{0}^{e}\right)+\mu_{0}\right] \\
x_{0 i}^{e}=m_{i} \bar{\pi}_{0}^{e}+n_{i} \bar{R}+q_{i} \bar{y}+\lambda_{i}\left[p_{i}\left(\bar{\pi}-\bar{\pi}_{0}^{e}\right)+\mu_{0}\right] .
\end{gathered}
$$

These expressions show that the impact of $x_{0}$ on $\bar{\pi}_{1}^{e}$ and $x_{0}^{e}$ is proportional to the difference $\bar{\pi}-\bar{\pi}_{0}^{e}$. In particular, when $\bar{\pi}<\bar{\pi}_{0}^{e}$ (credibility building stage), $x_{0}$ will be reduced 
proportionately to the difference $\bar{\pi}-\bar{\pi}_{0}^{e}$ and, if $0<\lambda_{i} p_{i}<1$, this will bring price setters' expectations about the inflation target down and closer to the actual target, $\bar{\pi}{ }^{13}$ In other words, provided that $0<\lambda_{i} p_{i}<1$, the public will be able to learn about the actual inflation target and this learning process will be more intense the closer $\lambda_{i} p_{i}$ is from 1 . The following corollary, which is demonstrated in the appendix, expresses this result not in terms of expected values but in terms of volatilities.

Corollary 1 Under both centralization and separation, the variance of the target level of inflation, $\bar{\pi}$, in period 1 is given by

$$
\Sigma_{1}^{\pi}=\left(1-\lambda_{i} p_{i}\right) \Sigma_{0}^{\pi}
$$

where $i=c, s(c=$ centralization case, and $s=$ separation case $)$.

The variance of the target level of inflation is multiplied by the factor $\left(1-\lambda_{i} p_{i}\right)$ after official intervention takes place. If $0<\lambda_{i} p_{i}<1$, the uncertainty about the target level of inflation will be reduced after official interventions occur (i.e., $\Sigma_{1}^{\pi}<\Sigma_{0}^{\pi}$ ). The factor $\left(1-\lambda_{i} p_{i}\right)$ is therefore a measure of the information content in official interventions about the inflation target. In this sense, if under a certain institutional setting the value of $\lambda p$ is larger than under an alternative setting, it allows for faster learning about the true inflation target and, therefore, permits faster credibility gains. In the next section the value of $\lambda p$ is investigated for both centralization and separation.

\section{Comparative Analysis Under Incomplete Informa- tion}

As stated, proposition 1 and corollary 1 are not very informative about the advantages and disadvantages of centralization and separation. In this section, the model is simulated in order compare the relative performances of centralized and separated

\footnotetext{
${ }^{13}$ While the focus of this paper is on central banks that need to gain anti-inflationary credibility, the intuition of the results also apply in a deflationary context where, on the contrary, the central bank needs to create positive inflationary expectations. Eggertsson (2003) argues that the purchase of foreign exchange can be an effective commitment device to a positive inflation target, helping to fight deflation in a liquidity trap. The intuition is that acquisition of foreign reserves by governments concerned with capital losses creates inflationary expectations, just as in the model of this paper However, in a deflationary context, this implies that more interventions should take place, not less.
} 
decisions in terms of learning about the inflation target and speed of accumulation of reserves.

\subsection{Simulation of Stage 0 Parameters}

The simulation of stage 0 parameters will show how the sensitivity of interventions to its four determinants $-\bar{\pi}_{0}^{e}, \bar{R},\left(\bar{\pi}-\bar{\pi}_{0}^{e}\right)$ and $\bar{y}$ - depends on the institutional setting (centralization versus separation). This requires assumptions about the underlying parameters. ${ }^{14}$ In particular, given a weight of $\alpha$ for the goal of targeting inflation, the weights attributed to the goals of output targeting and cost of intervention are assumed to be $\theta=0.3 \alpha$ and $\beta=0.1 \alpha$, respectively. ${ }^{15}$ The corresponding values of $m_{i}, n_{i}, p_{i}$, and $q_{i}$ for $i=c, s$ are then plotted for various values of $\gamma$, the weight of the reserve targeting goal (figure 2). ${ }^{16}$

Panel (a) in figure 2 shows how the coefficients of $\bar{\pi}_{0}^{e}\left(m_{i}, i=c, s\right)$ vary as $\gamma$ rises. It is clear $m_{c}$ and $m_{s}$ are equal for all values of $\gamma$, so interventions are equally sensitive to the direct effect of $\bar{\pi}_{0}^{e}$ in both institutional settings. It is also evident that $m_{c}$ and $m_{s}$ converge to zero as $\gamma$ rises. Similarly, panel (b) shows the values of the coefficients of $\bar{R}\left(n_{i}, i=c, s\right)$ as $\gamma$ increases. Both coefficients converge to 1 as $\gamma$ goes to infinity, but there is a persistent gap between $n_{c}$ and $n_{s}$, implying that official interventions are more sensitive to the target for reserves under centralization than under separation.

A more significant difference between centralization and separation occurs in panel (c), where the coefficients $p_{c}$ and $p_{s}$, which measure the sensitivity of intervention to $\left(\bar{\pi}-\bar{\pi}_{0}^{e}\right)$, are plotted. While both coefficients converge to zero as $\gamma$ goes to infinity, for positive values of $\gamma, p_{c}$ is significantly greater than $p_{s}$. This is an important result which shows that the amount intervened is much more sensitive under centralization than under separation to any gap between the true inflation target and the initial public's expectation about the target. In particular, if $\bar{\pi}$ is less than $\bar{\pi}_{0}^{e}$ (i.e., if the monetary

\footnotetext{
${ }^{14}$ Underlying parameters are the weights in the objective functions $(\theta, \alpha, \beta$ and $\gamma)$, the sensitivity of output to inflation surprises $(b)$, and the variances of the inflation target and intervention signal $\left(\Sigma_{0}^{\pi}\right.$ and $\sigma^{2}$ respectively).

${ }^{15}$ Simulations were performed for $\alpha=10$. It was also assumed that $b=1, \Sigma_{0}^{\pi}=1$ and $\sigma^{2}=10$. Various other combinations of parameter were tried and the qualitative results proved to be robust.

${ }^{16}$ The values of the coefficients $\lambda_{i}$ and $p_{i}$, for $i=c, s$ were obtained numerically with the aid of the software MATHEMATICA. These values were then used to compute $m_{i}, n_{i}, q_{i}$, for $i=c, s$.
} 
authority is in a process of acquiring anti-inflationary credibility), the term $p_{i}\left(\bar{\pi}-\bar{\pi}_{0}^{e}\right)$ will be negative in both cases, but will be significantly smaller under centralization than under separation. Therefore, the goal of accumulating reserves might be undermined by monetary authority's intention to build credibility, and this is particularly true when monetary and intervention decisions are centralized.

Panel (d) shows that, while under separation the amount intervened is positively affected by the output target, $\bar{y}$, it is negatively affected by $\bar{y}$ under centralization $\left(q_{s}>0\right.$ and $q_{c}<0$ ). Hence, separation again seems to be a more adequate institutional setting for the accumulation of reserves.

Panels (e) and (f) show how the learning rates about the inflation target can be significantly affected by the institutional arrangement. As discussed in the previous section, the quantity $\lambda p$ measures the speed of learning about the inflation target, with larger $\lambda p$ implying faster learning. Panel (e) plots both $\lambda_{c} p_{c}$ and $\lambda_{s} p_{s}$ and shows that, for positive $\gamma$, learning takes place at a faster pace when monetary and intervention decisions are centralized than when they are separated. Panel (f) shows that the difference in learning speeds achieves a maximum when $\gamma$ is about $15 \%$ of the weight attributed to the goal of stabilizing inflation. ${ }^{17}$

\footnotetext{
${ }^{17} \lambda_{c} p_{c}-\lambda_{s} p_{s}$ achieves its peak when $\gamma=1.5$. Since $\alpha=10$, this corresponds to $0.15 \alpha$.
} 
Figure 2. Simulation of Stage 0 Parameters

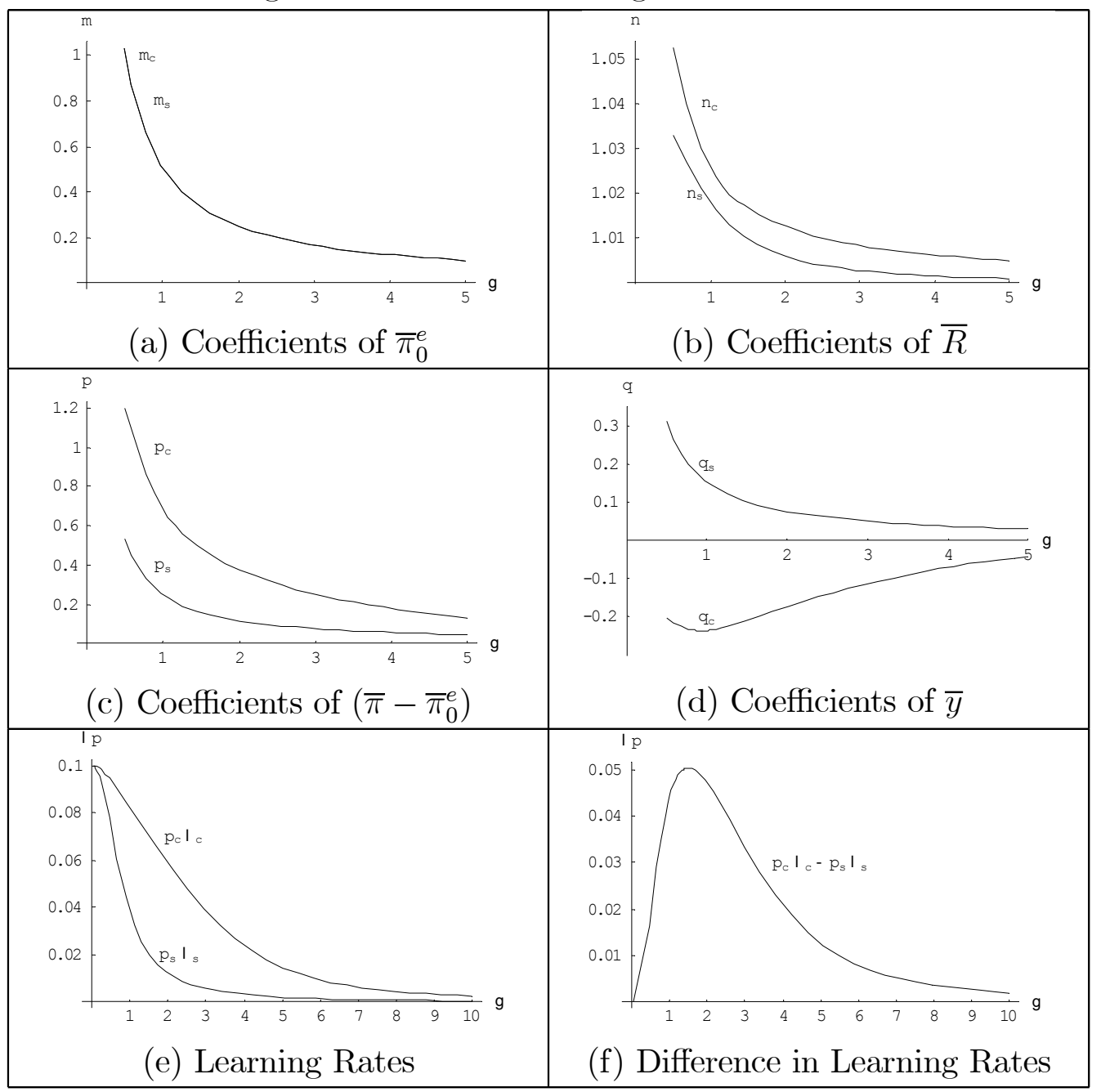

Intuitively, under centralization, official interventions affect inflation through two channels (the cost-of-intervention channel and the expectations channel), while under separation its impact is reduced to only one channel (the expectations channel). Therefore, under centralization, the link between future monetary policy decisions and current intervention policy decisions is stronger than under separation - in the spirit of Mussa (1981), centralized decisions lead to intervention choices that are more informative about future monetary policy. The market then uses the more informative intervention policy under centralization to make more accurate predictions about the inflation target than is possible under separation.

It should be noted, however, that the informational content advantage of centraliza- 
tion depends on the weight attributed to reserve targeting, $\gamma$. As seen in graph (e), for values of $\gamma$ close to the weight attributed to inflation targeting (a weight of 10 in our simulations), $\lambda_{c} p_{c}$ and $\lambda_{s} p_{s}$ are both very small and intervention decisions become almost entirely driven by the goal of targeting $\bar{R}$. In other words, for large $\gamma$, there is no significant learning about the target for inflation under either centralization or separation.

\subsection{The Trade-off Between Reserve Accumulation and Credi- bility Building}

Given the expression for intervention derived in proposition 1 (equation (14)) and the fact that $m_{c}=m_{s}$, the difference between intervention under separation and under centralization can be written as

$$
x_{0}^{s}-x_{0}^{c}=\left(n_{s}-n_{c}\right) \bar{R}+\left(p_{s}-p_{c}\right)\left(\bar{\pi}-\bar{\pi}_{0}^{e}\right)+\left(q_{s}-q_{c}\right) \bar{y}
$$

The simulations show that $n_{s}<n_{c}, p_{s}<p_{c}, q_{s}>q_{c}$, implying that the first term in the expression above will be negative, while the other two will be positive (assuming $\left.\bar{\pi}<\bar{\pi}_{0}^{e}\right)$. It is also reasonable to assume that $\bar{R}<\bar{y} .{ }^{18}$ With this assumption, and since $\left|n_{s}-n_{c}\right|<\left|q_{s}-q_{c}\right|$ (see panels (b) and (d) in figure 2), intervention is unquestionably larger under separation than under centralization. Furthermore, the bigger the difference between $\bar{\pi}$ and $\bar{\pi}_{0}^{e}$ the larger the positive gap between $x_{0}^{s}$ and $x_{0}^{c}$. Therefore, provided that $\gamma$ is not very large or very close to zero (implying that $p_{s}$ is significantly smaller than $p_{c}$ ), it will be more difficult to simultaneously pursue reserve accumulation and target a low inflation (relative to expectations) under centralization than under separation. This and previous findings can be summarized as follows.

For positive and finite positive values of $\gamma$ :

- When monetary policy and intervention policy decisions are centralized, learning by the public about the inflation target takes place at a faster pace than when decisions are separated.

\footnotetext{
${ }^{18}$ The assumption $\bar{R}<\bar{y}$ is equivalent to assuming that the value of foreign reserves measured in local currency is less than the nominal output target, $S \bar{R}<P \bar{y}$, which seems reasonable. To see this one could take $\log$ s of $S \bar{R}<P \bar{y}$ and rearrange to obtain $\log \bar{R}<\log \bar{y}+\log P-s=\log \bar{y}+\log P^{*}$, where the last equality follows from the relative purchasing power parity assumption. Given the normalization of foreign prices, $\log P^{*}=0$, this implies $\log \bar{R}<\log \bar{y}$ or, equivalently, $\bar{R}<\bar{y}$.
} 
- When monetary policy and intervention policy decisions are separated, international reserves can be accumulated at a faster pace than when decisions are centralized.

The first bullet results from the fact that interventions are more informative about future monetary policy when these decisions are more closely linked, that is, when they are centralized. The second bullet results from the greater isolation between monetary and intervention policies under separation. This isolation is what permits that greater speeds of accumulation of reserves are achieved without causing large adverse effects on inflationary expectations and on inflation itself. Therefore, the choice between centralization and separation involves a trade-off between accumulation of reserves, which can be better implemented under separation, and credibility building, which can be better obtained under centralization.

\subsection{Centralization versus Separation}

This section investigates what the trade-off between reserve accumulation and credibility building implies in terms of macroeconomic stability and reserve level management under both centralization and separation. Without loss of generality, the targets in the loss function are assumed to be $\bar{y}=\bar{\pi}=1$ and $\bar{R}=1 / 2 \cdot{ }^{19}$

\subsubsection{Macroeconomic Stability}

Macroeconomic stability is measured by the expected value of the loss function $\left.L^{M A}\right|_{i}=\theta\left(y_{1}-\bar{y}\right)^{2}+\alpha\left(\pi_{1}-\bar{\pi}\right)^{2}$, where the notation $\left.\right|_{i}$ indicates whether decisions are centralized $(i=c)$ or separated $(i=s)$. Figure 3 shows graphs of upper and side views of the difference in loss functions and its components, $E\left[\left(y_{1}-\bar{y}\right)^{2}\right]$ and $E\left[\left(\pi_{1}-\bar{\pi}\right)^{2}\right]$, as the inflation target prior $\left(\bar{\pi}_{0}^{e}\right)$ and weight or the reserve accumulation goal $(\gamma)$ vary. The behavior in all three cases is very similar, differing only in magnitudes. The side views are particularly illustrative of how separation provides a more stable economy than centralization for low values of $\gamma$ (meaning, roughly below 1.5) and how centralization becomes a better option when $\gamma$ is large. The upper view shows that the difference in

\footnotetext{
${ }^{19}$ The model was simulated with alternative parametrization and results were robust in qualitative terms.
} 
performance between centralization and separation is only significant when the government has low credibility with respect to its inflation target (that is, when $\bar{\pi}_{0}^{e}$ is sufficiently large). These results can be summarized as follows.

- When the target for inflation is credible, there is no significant difference in terms of macroeconomic stability between an institutional arrangement that separates monetary and intervention decisions and one in which these decisions are centralized.

- When the target for inflation lacks credibility and the weight placed in the goal of accumulating reserves is sufficiently large, the centralization of monetary and intervention policy decisions leads to a more stable economy in terms of both inflation and output.

- When the target for inflation lacks credibility and the weight placed in the goal of accumulating reserves is small enough, the separation of monetary and intervention policy decisions leads to a more stable economy in terms of both inflation and output.

Intuitively, when the public expects the monetary authority to target a level of inflation that is close to the actual target (i.e., when $\bar{\pi}_{0}^{e}$ is close to $\bar{\pi}$ ), there is little need to build credibility and, therefore, no significant role for interventions as a signalling device. In this case, the expectations channel will not be relevant and the expected inflation target on stage $1, \bar{\pi}_{1}^{e}$, will not differ much from $\bar{\pi}$ regardless of the size of interventions (this is clear from equation (17) and from the fact that $\bar{\pi}_{0}^{e}$ is nearly equal to $\bar{\pi}$ ). By the same token, when $\bar{\pi}_{0}^{e}$ is close to $\bar{\pi}, x_{0}^{e}$ will be a good forecast of $x_{0}$ and the cost-of-intervention channel will be virtually reduced to the term $\frac{\beta}{2 \alpha} x_{0}$. While this term will tend to make inflation under centralization bigger than under separation, it will not significantly affect output as the public is able to predict $x_{0}$ with good precision. In sum, when the prior $\bar{\pi}_{0}^{e}$ is close to the true target $\bar{\pi}$, not only the expectations channel will be limited but also the cost-of-intervention channel will be practically the same for both institutional arrangements, implying that the choice between centralized or separated decisions will not be of particular relevance. This can be seen in figure 3, where no significant difference exists in terms of macroeconomic stabilization between the two arrangements when $\bar{\pi}_{0}^{e}$ is close to $\bar{\pi}$ (as a reminder, $\bar{\pi}=1$ in the simulations). 
When $\bar{\pi}_{0}^{e}$ is substantially larger than $\bar{\pi}$, the ability to signal the true target for inflation via interventions becomes crucial for improving anti-inflationary credibility. As discussed before, there is no advantage for centralization in terms of the speed of learning about $\bar{\pi}$ when $\gamma$ is close to zero, but this advantage rises to a maximum when $\gamma$ approaches 1.5 and then disappears again as $\gamma$ goes to infinity (panels (e) and (f) of figure 2). In other words, for values of $\gamma$ close to 1.5, the expectations channel is very active, and centralization is able to stabilize the economy better than separation. This is why in figure 3 the initial larger loss under centralization decreases as $\gamma$ rises and eventually converges to zero for $\gamma$ sufficiently large.

Besides the expectations channel, the cost-of-intervention channel will also be more important in a scenario of lack of credibility. Because the public believes the monetary authority is targeting a larger level of inflation than in reality, it will also overestimate interventions, leading to an increase in the level of inflation under centralization relative to separation. Nonetheless, for large $\gamma$, the cost-of-intervention channel is less relevant as intervention will be closer to the reserve target $\bar{R}$ and, therefore, will be easier to predict.

In sum, for large $\bar{\pi}_{0}^{e}$ (relative to $\bar{\pi}$ ) and small $\gamma$, separation is a better strategy than centralization, since in this case the expectations channel is not very important for either centralization or separation and the cost-of-intervention channel causes inflation to be larger under centralization. For intermediate values of $\gamma$, the expectations channel becomes strong for centralization, surpassing the impact of the cost-of-intervention channel and making centralization a better arrangement in terms of macroeconomic stabilization. For large $\gamma$ the impact of both the expectations channel and the cost-of-intervention channel fade away, making the choice between centralization and separation irrelevant to macroeconomic stability. 
Figure 3. Macroeconomic Stability - Centralization versus Separation
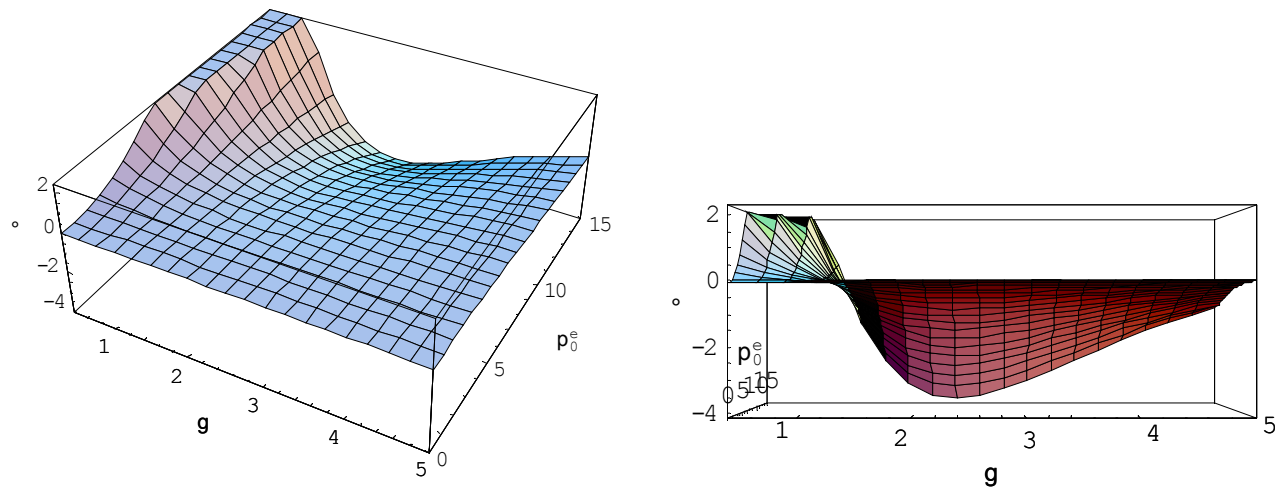

(a) $E\left[\left.\left(y_{1}-\bar{y}\right)^{2}\right|_{c}\right]-E\left[\left.\left(y_{1}-\bar{y}\right)^{2}\right|_{s}\right]$
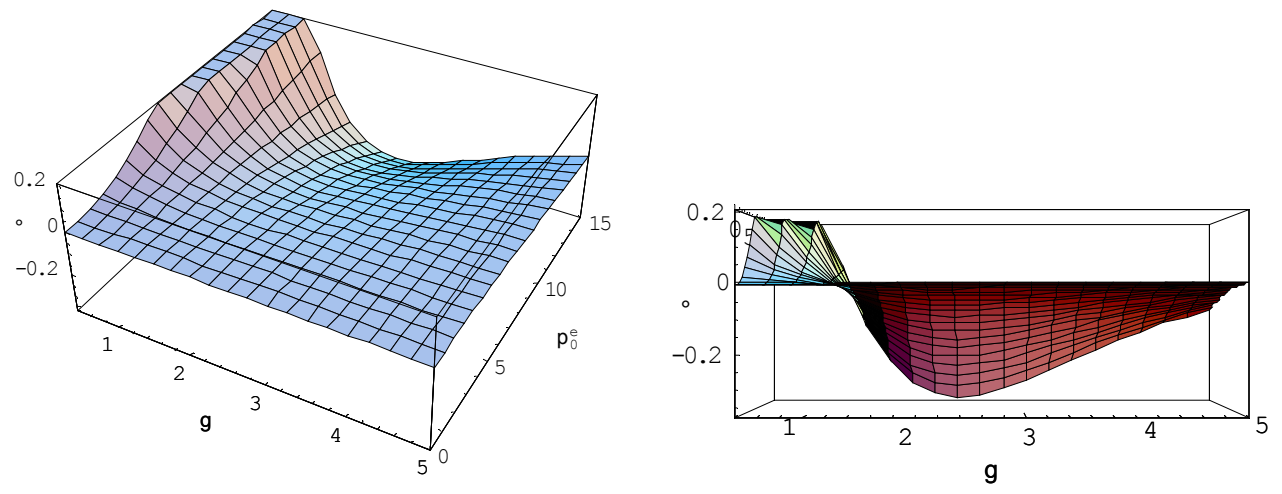

(b) $E\left[\left.\left(\pi_{1}-\bar{\pi}\right)^{2}\right|_{c}\right]-E\left[\left.\left(\pi_{1}-\bar{\pi}\right)^{2}\right|_{s}\right]$
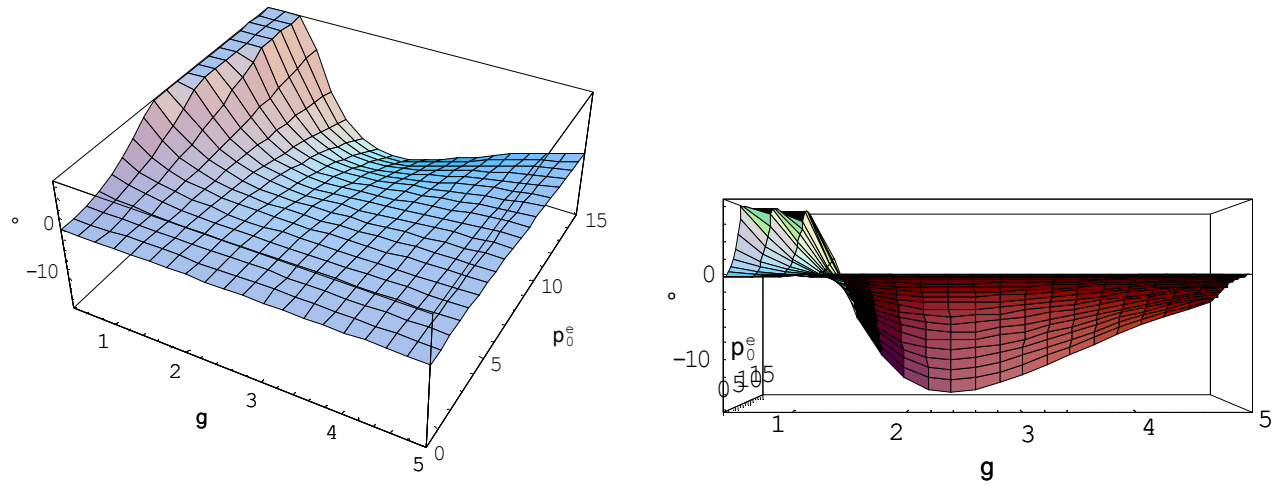

(c) $E\left[\left.L^{M A}\right|_{c}\right]-E\left[\left.L^{M A}\right|_{s}\right]$ 


\subsubsection{Reserve Targeting}

In this section, the expected value of the loss function $E\left[\left.L^{R}\right|_{i}\right]=E\left[\left.\left(\bar{R}-x_{0}\right)^{2}\right|_{i}\right], i=$ $c, s$, is simulated (figure 4). To interpret the simulation results, it is useful to remember the expression for intervention derived in proposition 1: $x_{0}=m_{i} \bar{\pi}_{0}^{e}+n_{i} \bar{R}+p_{i}\left(\bar{\pi}-\bar{\pi}_{0}^{e}\right)+q_{i} \bar{y}$ for $i=c, s$.

As shown in figure 2 , as $\gamma$ increases the coefficients $m_{i}, p_{i}$ and $q_{i}$ all converge to zero while the coefficient $n_{i}$ tends to 1 . Hence, for both centralization and separation, when the weight on the goal of targeting reserves goes to infinity, $x_{0}$ converges to $\bar{R}$ and, consequently, $E\left[\left.L^{R}\right|_{c}\right]$ and $E\left[\left.L^{R}\right|_{s}\right]$ converge to zero regardless of the value of $\bar{\pi}_{0}^{e}$.

For small values of $\gamma$ there are significant differences between centralization and separation. As shown before, the direct effect of $\bar{\pi}_{0}^{e}$ on $x_{0}$ is the same under both institutional arrangements $\left(m_{c}=m_{s}\right)$, but the effect related to the lack of credibility of the target (captured by the difference $\bar{\pi}-\bar{\pi}_{0}^{e}$ ) is bigger under centralization than under separation (i.e. $p_{c}>p_{s}$ ). Furthermore, recurring to figure 2, we see that $p_{c}$ is larger than $m_{c}$ for small values of $\gamma$, but as $\gamma$ rises and the impact of the lack of credibility on interventions fades away, $p_{c}$ eventually becomes smaller than $m_{c}$. This explains panel (a) in figure 4, which shows that for sufficiently small values of $\gamma$ the loss function $E\left[\left.L^{R}\right|_{c}\right]$ is decreasing in $\bar{\pi}_{0}^{e}$ but, for intermediate values of $\gamma, E\left[\left.L^{R}\right|_{c}\right]$ becomes increasing in $\bar{\pi}_{0}^{e}$ and eventually converges to zero as $\gamma$ rises to infinity. In the case of separation, the sensitivity of interventions to the lack of credibility of the target is always smaller and less significant than the direct impact that $\bar{\pi}_{0}^{e}$ has on interventions. That is why in panel (b) the loss function is increasing in $\bar{\pi}_{0}^{e}$ for small and intermediate values of $\gamma$ and eventually converges to zero - regardless of the value of $\bar{\pi}_{0}^{e}-$ as $\gamma$ rises.

Panel (c) shows that, for small and intermediate values of both $\gamma$ and $\bar{\pi}_{0}^{e}$, centralization is always a better strategy than separation for achieving the targeted reserve level. For intermediate values of $\gamma$ (close to 1.5) and large values of $\bar{\pi}_{0}^{e}$, separation becomes a superior institutional setting in terms of reserve accumulation due to the greater isolation between monetary and intervention decisions. As $\gamma$ goes to infinity the two institutional settings perform equally well, regardless of the size of $\bar{\pi}_{0}^{e}$. 
Figure 4. Reserve Targeting - Centralization versus Separation
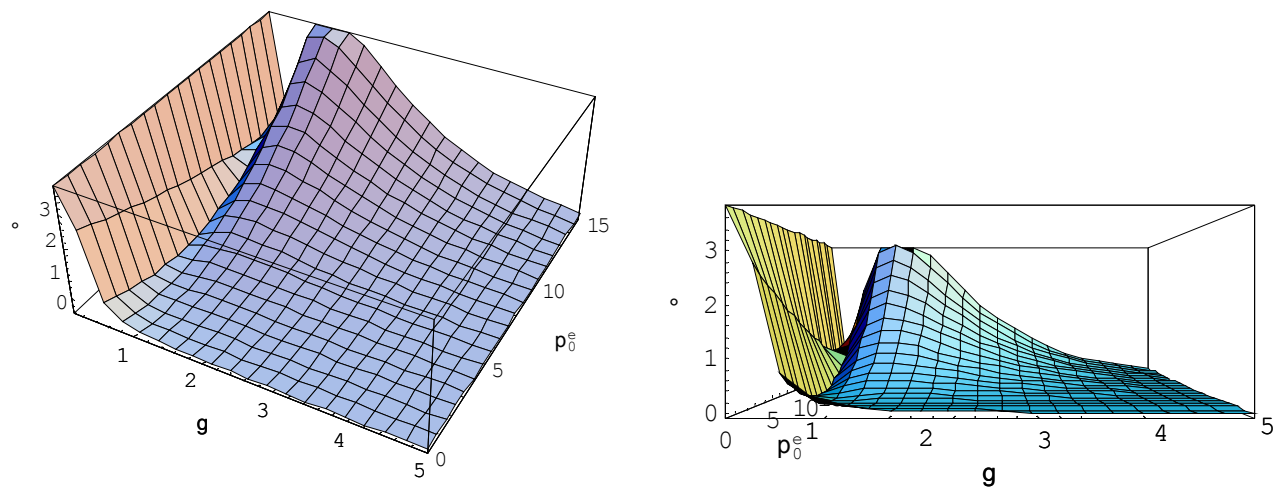

(a) $E\left[\left.L^{R}\right|_{c}\right]$
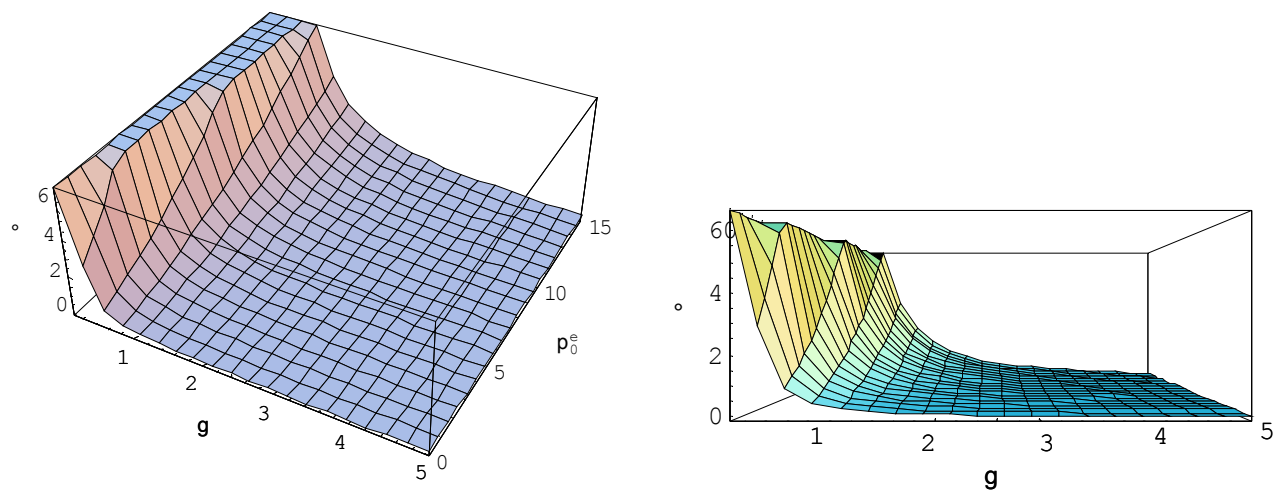

(b) $E\left[\left.L^{R}\right|_{s}\right]$
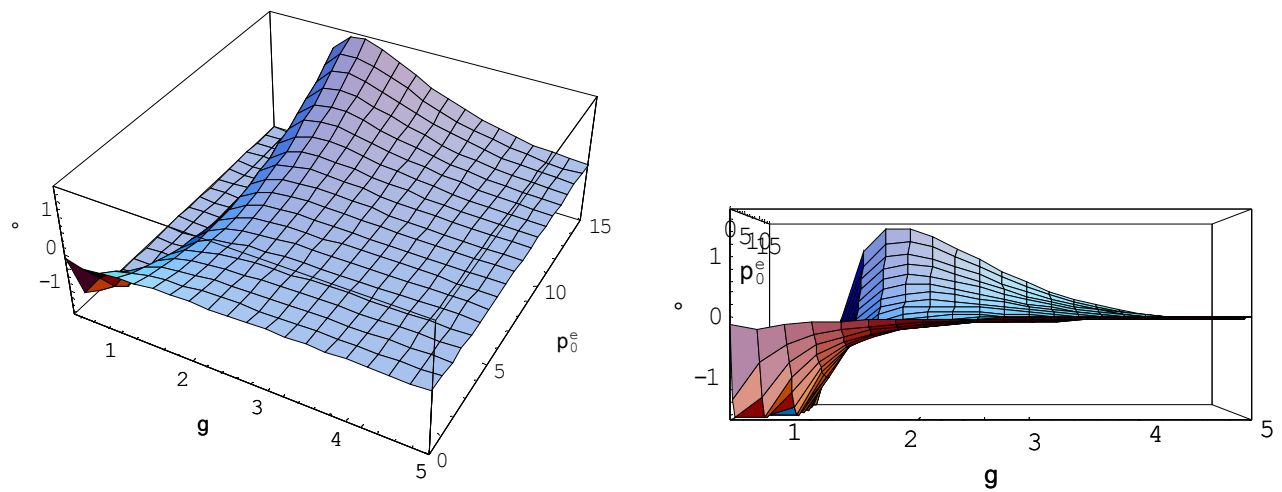

(c) $E\left[\left.L^{R}\right|_{c}\right]-E\left[\left.L^{R}\right|_{s}\right]$ 


\subsubsection{Discussion}

Figures 3 and 4 illustrate the trade-offs involved in the choice of an institutional setting that establishes the division of responsibilities between monetary and intervention policies. In particular, panels (c) of figures 3 and 4 show that neither separation nor centralization is a superior arrangement in all circumstances - authorities can only choose to accumulate reserves faster at the cost of having a less stable economy. Therefore, the trade-off previously identified between credibility improvements and accumulation of reserves in stage 0 translates into a trade-off between macroeconomic stability and accumulation of reserves in stage 1. In fact, for large enough values of $\gamma$, fast reserve accumulation can be achieved by separating monetary and intervention decisions, but this will produce a less stable economy as the signalling about the actual inflation targeting will be weakened. For small values of $\gamma$, on the other hand, reserves can be build faster by choosing to centralize monetary and intervention decisions, but this will also generate a less stable economy since interventions will have a greater impact on inflation through the cost-of-intervention channel.

Therefore, the choice of institutional arrangement depends on the value of $\gamma$, raising the question of what the typical value of this parameter is. This cannot be answered precisely, but it is possible to conjecture what values for $\gamma$ are reasonable. First, $\gamma$ is expected to be significantly larger than $\beta$, meaning that reserve accumulation is typically a more important goal than speculative motives to intervene. In fact, as recent surveys have shown (Neely, 2001), the later objective does not seem to be an important motivation for intervening. Second, the reserve targeting goal is not expected to be more important than the goal of stabilizing output. These conjectures suggest that the range of possible values for $\gamma$ is restricted to a much smaller interval than the interval of 0 to 5 depicted in the figures 3 and 4 . As an illustration, assume that the value of $\gamma$ is confined to the interval of $\gamma=2 \beta=2$ to $\gamma=\theta=3$. Under these assumptions, the graphs (c) in figure 3 and 4 show that faster reserve accumulation can be achieved by separating monetary and intervention decisions, while anti-inflationary credibility can be improved more quickly by centralizing these decisions.

Interestingly, these results differ from Vitale (2003), whose analysis advocates that the separation between monetary policy and foreign exchange interventions is always a superior institutional arrangement relative to centralization. The distinct conclusions result from the fact that in Vitale's model interventions are pursued only for speculative 
reasons, while in the present paper interventions also aim at achieving a certain level of foreign reserves.

\section{Concluding Remarks}

A theoretical framework was developed to study the implementation of official interventions in the foreign exchange market when policymakers allow exchange rates to float and have the simultaneous goals of macroeconomic stabilization and foreign reserve accumulation. The model takes into account the connection between sterilized official interventions in the foreign exchange market and monetary policy decisions, which is usually absent in the literature. This was done by incorporating in the policymakers' objective function a term that captures the cost of intervention (as in Battacharya and Weller, 1997, and Vitale, 2003), which permits exploring the interaction between monetary and intervention decisions in a spirit similar to Mussa's conjecture (Mussa, 1981).

In the case where policymakers' goals are known by price setters (complete information case), monetary policy can be isolated from the adverse effects of intervention policy by delegating the later to an independent authority. In other words, the simple separation between monetary and intervention policy decisions is sufficient to avoid the influence of the later over the former, leading to a better outcome in terms of macroeconomic stabilization. The intuition for this result is that the separation of intervention policy decisions allows monetary policy to be implemented without internalizing the costs of intervention. In terms of achieving the reserve targeting goal, results are not clear-cur and both separation and centralization may be the best arrangement under reasonable calibration choices.

Under incomplete information, the separation of monetary and intervention decisions is no longer able to fully isolate monetary policy from the influence of intervention decisions. The reason is that intervention decisions now have an impact on the public's expectations about the monetary authority's goal for inflation, and this happens even if the costs of intervention are not internalized by the monetary authority. As a consequence, under incomplete information, larger interventions lead to an increase in the expected inflation target and a rise in the inflation rate itself.

Simulations for the incomplete information case uncover a trade-off between reserve 
accumulation and credibility building: fast reserve accumulation may harm the antiinflationary credibility of the monetary authority or, conversely, fast improvements in anti-inflationary credibility may reduce the ability of the government to accumulate reserves. The simulation of loss functions showed that this trade-off translates into a trade-off between reserve accumulation and macroeconomic stability. As in the complete information case, and contrary to previous work, neither centralization nor separation can be considered a superior arrangement in terms of both macroeconomic stability and reserve targeting. Instead, under reasonable parametric assumptions, separation is a better arrangement in order to accumulate reserves fast while centralization is a better arrangement in terms of achieving macroeconomic stability.

The theoretical framework presented here represents another step towards a better understanding of the link between sterilized interventions and monetary policy, specially when reserve accumulation is part of policymakers' goals. Importantly, the results illustrate the relevance of rather overlooked institutional features of macroeconomic policymaking in open economies. Future research could seek to explore a dynamic version of the model, which would be particularly interesting in the case of incomplete information, as it would show how results are affected by the inclusion of various stages of interaction and learning. Also, the case of uncertainty about the target for reserves could possibly yield fruitful insights. 


\section{References}

[1] Backus, David and John Driffill, 1985, "Inflation and Reputation," American Economic Review, vol. 75(3), p. 530-38.

[2] Barro, Robert J., and D. Gordon, 1983, "Rules, Discretion, and Reputation in a Model of Incomplete Information," Journal of Monetary Economics, 12, 101120.

[3] Barro, Robert J., 1986, "Reputation in a Model of Monetary Policy with Incomplete Information," Journal of Monetary Economics, 17, 1-20.

[4] Bhattacharya, Utpal, and Paul Weller, 1997, "The Advantage to Hiding One's Hand: Speculation and Central Bank Intervention in the Foreign Exchange Market," Journal of Monetary Economics, Vol. 39, p. 251-277.

[5] Dominguez, Katherine and Jeffrey Frankel, 1993a, Does Foreign Exchange Intervention Work?, Institute of International Economics, Washington D.C.

[6] Dominguez, Katherine and Jeffrey Frankel, 1993b, "Foreign Exchange Intervention Matter: An Empirical Assessment", in On Exchange Rates, J. Frenkel (ed.), The MIT Press, Cambridge MA.

[7] Edison, Hali, 1993, "The Effectiveness of Central Bank Intervention: A Survey of the Literature After 1982," Princeton University, Department of Economics, Special Paper in International Economics, No. 18.

[8] Eggertsson, Gauti B., "How to fight deflation in a liquidity trap: committing to being irresponsible," IMF Working Paper, WP/03/64 (Washington: International Monetary Fund).

[9] Granger, C. W. J., and Paul Newbold, Forecasting Economic Time Series, second edition, Academic Press, Orlando, FL. 
[10] Jeanne, Olivier, and Romain Ranciere, 2006, "The optimal level of international reserves in emerging market countries: formulas and applications," IMF Working Paper 06/229 (Washington: International Monetary Fund).

[11] Kaminsky, Graciela, and Karen Lewis, 1996, "Does foreign exchange intervention signal future monetary policy?," Journal of Monetary Economics, Vol. 37, pages 285-312.

[12] Lewis, Karen, 1995, "Are the Foreign Exchange Intervention and Monetary Policy Relates and Does it Really Matter?," Journal of Business, Vol. 68, No. 2.

[13] Lyons, Richard, 2001, The Microstructure Approach to Exchange Rates, The MIT Press (Cambridge, Massachusetts).

[14] Moser-Boehm, Paul, 2005, "Governance Aspects of Foreign Exchange Interventions," BIS Papers, No. 24, Foreign Exchange Market Intervention in Emerging Markets: Motives, Techniques and Implications, Monetary and Economic Department, Bank of International Settlement.

[15] Mussa, Michael, 1981, The Role of Official Intervention, Group of Thirty, New York. [16] Neely, Christopher, 2001, "The Practice of Central Bank Intervention: Looking Under the Hood," Central Banking 11, p. 24-37, Federal Reserve Bank of Saint Louis.

[17] Obstfeld , Maurice, and Kenneth Rogoff, 1998, "Foundations of International Macroeconomics," The MIT Press: Cambridge, Massachusetts.

[18] Sarno, Lucio, and Mark P. Taylor, 2001, "Official Intervention in the Foreign Exchange Market: Is it Effective, and, If so, How Does it Work?," Journal of Economic Literature, Vol. 39, No. 3, p. 839-868.

[19] Schwartsman, Alexandre, 2004, "A "Nova Politica Cambial" Nao e Nova," Folha de Sao Paulo (in Portuguese). 
[20] Stein, J., 1989, "Cheap Talk and the Fed: A Theory of Imprecise Announcements," American Economic Review, 79, p. 32-42.

[21] Vitale, Paolo, 1999, "Sterilised Central Bank Intervention in the Foreign Exchange Market," Journal of International Economics, Vol. 49, p. 245-267.

[22] Vitale, Paolo, 2003, "Foreign Exchange Intervention: How to Signal Policy Objectives and Stabilise the Economy," Journal of Monetary Economics, Vol. 50, p. 841-870. 


\section{Appendix}

\section{Proof of Proposition 1}

Since $\bar{\pi}$ and $\mu_{0}$ are normally distributed, the projection theorem for normal distributions $^{20}$ can be used to update agents expectations about $\bar{\pi}$ and $x_{0}$ based on the observation of $x_{0}+\mu_{0}$. Calling $I_{0}=x_{0}+\mu_{0}$, this yields:

$$
\begin{gathered}
\bar{\pi}_{1}^{e} \equiv E\left[\bar{\pi} \mid I_{0}\right]=\bar{\pi}_{0}^{e}+\lambda\left[I_{0}-E\left(I_{0}\right)\right], \\
x_{0}^{e} \equiv E\left[x \mid I_{0}\right]=E\left(I_{0}\right)+\lambda\left[I_{0}-E\left(I_{0}\right)\right],
\end{gathered}
$$

where $\lambda=\Sigma_{\bar{\pi}, I_{0}} \Sigma_{I_{0}, I_{0}}^{-1}$ and $\Sigma_{a, b}=\operatorname{Cov}(a, b)$ for any random variables $a$ and $b . E(\cdot)$ represents unconditional expectations, while $E\left[\cdot \mid I_{0}\right]$ represents the expectation conditional on observing $I_{0}$.

\section{Centralization Case}

The problem of the monetary authority in stage 0 is

$$
\begin{gathered}
\operatorname{Min}_{x_{0}} E\left[\theta\left(y_{1}-\bar{y}\right)^{2}+\alpha\left(\pi_{1}-\bar{\pi}\right)^{2}+\gamma\left(\bar{R}-x_{0}\right)^{2}+\beta\left(s_{0}-s_{1}\right) x_{0} \mid \Omega_{M A}\right] \\
\text { s.t. }\left\{\begin{array}{c}
\pi_{1}^{e}=\bar{\pi}_{1}^{e}+\frac{b \theta}{\alpha} \bar{y}+\frac{\beta}{2 \alpha} x_{0}^{e} \\
y_{1}=b\left(\pi_{1}-\pi_{1}^{e}\right) \\
s_{1}-s_{0}=\pi_{1} \\
\pi_{1}=\bar{\pi}+\frac{b \theta}{\alpha} \bar{y}+\frac{\beta}{2 \alpha} x_{0}+\frac{b^{2} \theta}{\alpha+b^{2} \theta}\left[\left(\bar{\pi}_{1}^{e}-\bar{\pi}\right)+\frac{\beta}{2 \alpha}\left(x_{0}^{e}-x_{0}\right)\right] \\
\bar{\pi}_{1}^{e}=\bar{\pi}_{0}^{e}+\lambda_{c}\left[I_{0}-E\left(I_{0}\right)\right] \\
x_{0}^{e}=E\left(I_{0}\right)+\lambda_{c}\left[I_{0}-E\left(I_{0}\right)\right]
\end{array}\right.
\end{gathered}
$$

where $\Omega_{M A}$ is the information set available to the monetary authority in stage 0 , which excludes the realization of $\mu_{0}$.

The problem above can only be solved if a functional form for $x_{0}$ is assumed. The solution has to be obtained "by construction" as is common practice in the microstructure

\footnotetext{
${ }^{20}$ This theorem states that, given two jointly normally distributed random variables $\mathrm{A}$ and $\mathrm{B}$ such that

$\left[\begin{array}{l}A \\ B\end{array}\right] \sim N\left(\left[\begin{array}{l}\bar{A} \\ \bar{B}\end{array}\right],\left[\begin{array}{cc}\Sigma_{A A} & \Sigma_{A B} \\ \Sigma_{B A} & \Sigma_{B B}\end{array}\right]\right)$, the distribution of $A$ conditional on $B=b$ is also normal with mean $E[A \mid b]=\bar{A}+\Sigma_{A B} \Sigma_{B B}^{-1}(b-\bar{B})$. See Granger and Newbold (1986), p. 298-299.
} 
literature on exchange rates (see Lyons, 2001, p. 70). This means that a functional form for $x_{0}$ will be proposed and then its consistency with equilibrium agents' expectations will be verified. The proposed solution has the form

$$
x_{0}=m_{c} \bar{\pi}_{0}^{e}+n_{c} \bar{R}+p_{c}\left(\bar{\pi}-\bar{\pi}_{0}^{e}\right)+q_{c} \bar{y},
$$

where $m_{c}, n_{c}, p_{c}$, and $q_{c}$ are constants. With this functional form, equations (18) and (19) become

$$
\begin{gathered}
\bar{\pi}_{1}^{e}=E\left[\bar{\pi} \mid I_{0}\right]=\bar{\pi}_{0}^{e}+\lambda_{c}\left[I_{0}-m_{c} \bar{\pi}_{0}^{e}-n_{c} \bar{R}-q_{c} \bar{y}\right], \\
x_{0}^{e}=E\left[x \mid I_{0}\right]=m_{c} \bar{\pi}_{0}^{e}+n_{c} \bar{R}+q_{c} \bar{y}+\lambda_{c}\left[I_{0}-m_{c} \bar{\pi}_{0}^{e}-n_{c} \bar{R}-q_{c} \bar{y}\right],
\end{gathered}
$$

where $\lambda_{c}=\frac{p_{c} \Sigma_{0}^{\pi}}{p_{c}^{2} \Sigma_{0}^{\pi}+\sigma^{2}}$.

Inserting these expressions in equation (12) and in the equation for $\pi_{1}^{e}$, plugging the resulting expressions in the objective function of the intervention authority, and taking its first order derivative yields

$$
\begin{aligned}
x_{0}= & \left\{\frac{b^{2} m_{c} \beta^{2} \theta\left(\lambda_{c}-1\right)^{2}+2 b^{2} \alpha \beta \theta\left[1+2 m_{c}\left(\lambda_{c}-1\right) \lambda_{c}\right]+2 \alpha^{2}\left(\beta+2 b^{2} m_{c} \theta \lambda_{c}^{2}\right)}{\alpha\left[4 \gamma\left(\alpha+b^{2} \theta\right)-\beta^{2}\right]-2 b^{2} \beta(2 \alpha+\beta) \theta \lambda_{c}+b^{2}(2 \alpha+\beta)^{2} \theta \lambda_{c}^{2}}\right\} \bar{\pi}_{0}^{e} \\
& +\left\{\frac{b^{2} n_{c} \beta^{2} \theta\left(\lambda_{c}-1\right)^{2}+4 b^{2} \alpha \theta\left[\gamma+n_{c} \beta\left(\lambda_{c}-1\right) \lambda_{c}\right]+4 \alpha^{2}\left(\gamma+b^{2} n_{c} \theta \lambda_{c}^{2}\right)}{\alpha\left[4 \gamma\left(\alpha+b^{2} \theta\right)-\beta^{2}\right]-2 b^{2} \beta(2 \alpha+\beta) \theta \lambda_{c}+b^{2}(2 \alpha+\beta)^{2} \theta \lambda_{c}^{2}}\right\} \bar{R} \\
& +\left\{\frac{2 \alpha\left[\alpha \beta+b^{2}(2 \alpha+\beta) \theta \lambda_{c}\right]}{\alpha\left[4 \gamma\left(\alpha+b^{2} \theta\right)-\beta^{2}\right]-2 b^{2} \beta(2 \alpha+\beta) \theta \lambda_{c}+b^{2}(2 \alpha+\beta)^{2} \theta \lambda_{c}^{2}}\right\}\left(\bar{\pi}-\bar{\pi}_{0}^{e}\right) \\
& +\left\{-\frac{b \theta\left[\beta\left(\lambda_{c}-1\right)+2 \alpha \gamma\right]\left[2 \alpha+b q_{c} \beta+2 b^{2} \theta-b q_{c}(2 \alpha+\beta) \lambda_{c}\right]}{\alpha\left[4 \gamma\left(\alpha+b^{2} \theta\right)-\beta^{2}\right]-2 b^{2} \beta(2 \alpha+\beta) \theta \lambda_{c}+b^{2}(2 \alpha+\beta)^{2} \theta \lambda_{c}^{2}}\right\} \bar{y} .
\end{aligned}
$$

To have a Nash equilibrium, the conjecture about the functional form for $x_{0}$ has to 
be consistent with the expression above. This implies that

$$
\begin{aligned}
m_{c} & =\frac{b^{2} m_{c} \beta^{2} \theta\left(\lambda_{c}-1\right)^{2}+2 b^{2} \alpha \beta \theta\left[1+2 m_{c}\left(\lambda_{c}-1\right) \lambda_{c}\right]+2 \alpha^{2}\left(\beta+2 b^{2} m_{c} \theta \lambda_{c}^{2}\right)}{\alpha\left[4 \gamma\left(\alpha+b^{2} \theta\right)-\beta^{2}\right]-2 b^{2} \beta(2 \alpha+\beta) \theta \lambda_{c}+b^{2}(2 \alpha+\beta)^{2} \theta \lambda_{c}^{2}}, \\
n_{c} & =\frac{b^{2} n_{c} \beta^{2} \theta\left(\lambda_{c}-1\right)^{2}+4 b^{2} \alpha \theta\left[\gamma+n_{c} \beta\left(\lambda_{c}-1\right) \lambda_{c}\right]+4 \alpha^{2}\left(\gamma+b^{2} n_{c} \theta \lambda_{c}^{2}\right)}{\alpha\left[4 \gamma\left(\alpha+b^{2} \theta\right)-\beta^{2}\right]-2 b^{2} \beta(2 \alpha+\beta) \theta \lambda_{c}+b^{2}(2 \alpha+\beta)^{2} \theta \lambda_{c}^{2}}, \\
p_{c} & =\frac{2 \alpha\left[\alpha \beta+b^{2}(2 \alpha+\beta) \theta \lambda_{c}\right]}{\alpha\left[4 \gamma\left(\alpha+b^{2} \theta\right)-\beta^{2}\right]-2 b^{2} \beta(2 \alpha+\beta) \theta \lambda_{c}+b^{2}(2 \alpha+\beta)^{2} \theta \lambda_{c}^{2}}, \\
q_{c} & =-\frac{b \theta\left[\beta\left(\lambda_{c}-1\right)+2 \alpha \gamma\right]\left[2 \alpha+b q_{c} \beta+2 b^{2} \theta-b q_{c}(2 \alpha+\beta) \lambda_{c}\right]}{\alpha\left[4 \gamma\left(\alpha+b^{2} \theta\right)-\beta^{2}\right]-2 b^{2} \beta(2 \alpha+\beta) \theta \lambda_{c}+b^{2}(2 \alpha+\beta)^{2} \theta \lambda_{c}^{2}},
\end{aligned}
$$

Solving this system, the values for the coefficient of equation (20) are

$$
\begin{aligned}
m_{c} & =\frac{2 \alpha \beta}{4 \alpha \gamma-\beta^{2}}, \\
n_{c} & =\frac{4 \alpha \gamma}{4 \alpha \gamma-\beta^{2}}, \\
p_{c} & =\frac{2 \alpha\left[\alpha \beta+b^{2}(2 \alpha+\beta) \theta \lambda_{c}\right]}{\alpha\left[4 \gamma\left(\alpha+b^{2} \theta\right)-\beta^{2}\right]-2 b^{2} \beta(2 \alpha+\beta) \theta \lambda_{c}+b^{2}(2 \alpha+\beta)^{2} \theta \lambda_{c}^{2}}, \\
q_{c} & =-\frac{2 b \theta\left[\beta\left(\lambda_{c}-1\right)+2 \alpha \lambda_{c}\right]}{4 \alpha \gamma-\beta^{2}},
\end{aligned}
$$

where $\lambda_{c}$ satisfies the second order condition $\alpha\left[4 \gamma\left(\alpha+b^{2} \theta\right)-\beta^{2}\right]-2 b^{2} \beta(2 \alpha+\beta) \theta \lambda_{c}+$ $b^{2}(2 \alpha+\beta)^{2} \theta \lambda_{c}^{2}>0$ and solves the equation $\lambda_{c}=\frac{p_{c} \Sigma_{0}^{\pi}}{p_{c}^{2} \Sigma_{0}^{\pi}+\sigma^{2}}$. Hence, with the values of the coefficients in equation (20) given as above, the proposed functional form for $x_{0}$ is consistent with agents' expectations and is therefore a Nash equilibrium of the problem.

Separation Case

In this case, the problem of the intervention authority is

$$
\begin{gathered}
\operatorname{Min}_{x_{0}} E\left[\gamma\left(\bar{R}-x_{0}\right)^{2}+\beta\left(s_{0}-s_{1}\right) x_{0} \mid \Omega_{I N T}\right] \\
\text { s.t. }\left\{\begin{array}{c}
s_{1}-s_{0}=\pi_{1} \\
\pi_{1}=\bar{\pi}+\frac{b \theta}{\alpha} \bar{y}+\frac{\beta}{2 \alpha} x_{0}+\frac{b^{2} \theta}{\alpha+b^{2} \theta}\left(\bar{\pi}_{1}^{e}-\bar{\pi}\right) \\
\bar{\pi}_{1}^{e}=\bar{\pi}_{0}^{e}+\lambda_{d}\left[I_{0}-E\left(I_{0}\right)\right]
\end{array}\right.
\end{gathered}
$$


where $\Omega_{I N T}$ is the information set available to the intervention authority in stage 0 , which excludes the realization of $\mu_{0}$.

As before, the problem above cannot be solved unless a functional form for $x_{0}$ is assumed. A reasonable conjecture is

$$
x_{0}=m_{s} \bar{\pi}_{0}^{e}+n_{s} \bar{R}+p_{s}\left(\bar{\pi}-\bar{\pi}_{0}^{e}\right)+q_{s} \bar{y} .
$$

Note that this is the same form assumed for the case of centralization. The only difference stems from the potentially different coefficients in the equation above, which now have a subscript $s$ to denote that this is the case of separation.

With this functional form, equations (18) and (19) become

$$
\begin{gathered}
\bar{\pi}_{1}^{e}=E\left[\bar{\pi} \mid I_{0}\right]=\bar{\pi}_{0}^{e}+\lambda_{s}\left[I_{0}-m_{s} \bar{\pi}_{0}^{e}-n_{s} \bar{R}-q_{s} \bar{y}\right], \\
x_{0}^{e}=E\left[x \mid I_{0}\right]=m_{s} \bar{\pi}_{0}^{e}+n_{s} \bar{R}+q_{s} \bar{y}+\lambda_{s}\left[I_{0}-m_{s} \bar{\pi}_{0}^{e}-n_{s} \bar{R}-q_{s} \bar{y}\right],
\end{gathered}
$$

where $\lambda_{s}=\frac{p_{s} \Sigma_{0}^{\pi}}{p_{s}^{2} \Sigma_{0}^{\pi}+\sigma^{2}}$.

Inserting these expressions in equation (13) and in the equation for $\pi_{1}^{e}$, plugging the resulting expressions in the objective function of the monetary authority, and taking its first order derivative,

$$
\begin{aligned}
x_{0}= & \left\{\frac{\beta\left[\alpha+b^{2} \theta\left(1-m_{s} \lambda_{s}\right)\right]}{2\left[\alpha \gamma+b^{2} \theta\left(\gamma-\beta \lambda_{s}\right)\right]}\right\} \bar{\pi}_{0}^{e}+\left\{\frac{2 \alpha \gamma+b^{2} \theta\left(2 \gamma-n_{s} \beta \lambda_{s}\right)}{2\left[\alpha \gamma+b^{2} \theta\left(\gamma-\beta \lambda_{s}\right)\right]}\right\} \bar{R} \\
& +\left\{\frac{\alpha \beta}{2\left[\alpha \gamma+b^{2} \theta\left(\gamma-\beta \lambda_{s}\right)\right]}\right\}\left(\bar{\pi}-\bar{\pi}_{0}^{e}\right)+\left\{\frac{b \beta \theta\left(\alpha+b^{2} \theta-b \alpha q_{s} \lambda_{s}\right)}{2\left[\alpha \gamma+b^{2} \theta\left(\gamma-\beta \lambda_{s}\right)\right]}\right\} \bar{y} .
\end{aligned}
$$

To have a Nash equilibrium, the conjecture about the functional form for $x_{0}$ has to be consistent with the expression above. This implies that

$$
\begin{aligned}
m_{s} & =\frac{\beta\left[\alpha+b^{2} \theta\left(1-m_{s} \lambda_{s}\right)\right]}{2\left[\alpha \gamma+b^{2} \theta\left(\gamma-\beta \lambda_{s}\right)\right]} \\
n_{s} & =\frac{2 \alpha \gamma+b^{2} \theta\left(2 \gamma-n_{s} \beta \lambda_{s}\right)}{2\left[\alpha \gamma+b^{2} \theta\left(\gamma-\beta \lambda_{s}\right)\right]}, \\
p_{s} & =\frac{\alpha \beta}{2\left[\alpha \gamma+b^{2} \theta\left(\gamma-\beta \lambda_{s}\right)\right]}, \\
q_{s} & =\frac{b \beta \theta\left(\alpha+b^{2} \theta-b \alpha q_{s} \lambda_{s}\right)}{2\left[\alpha \gamma+b^{2} \theta\left(\gamma-\beta \lambda_{s}\right)\right]} .
\end{aligned}
$$


Solving this system,

$$
\begin{aligned}
m_{s} & =\frac{\beta\left(\alpha+b^{2} \theta\right)}{2 \alpha \gamma+b^{2} \theta\left(2 \gamma-\beta \lambda_{s}\right)}, \\
n_{s} & =\frac{2 \gamma\left(\alpha+b^{2} \theta\right)}{2 \alpha \gamma+b^{2} \theta\left(2 \gamma-\beta \lambda_{s}\right)}, \\
p_{s} & =\frac{\alpha \beta}{2\left[\alpha \gamma+b^{2} \theta\left(\gamma-\beta \lambda_{s}\right)\right]}, \\
q_{s} & =\frac{b \beta \theta\left(\alpha+b^{2} \theta\right)}{\alpha\left[2 \alpha \gamma+b^{2} \theta\left(2 \gamma-\beta \lambda_{s}\right)\right]},
\end{aligned}
$$

where $\lambda_{s}$ satisfies the second order condition $\lambda_{s}<\frac{\gamma\left(\alpha+b^{2} \theta\right)}{b^{2} \beta \theta}$ and solves the equation $\lambda_{s}=\frac{p_{s} \Sigma_{0}^{\pi}}{p_{s}^{2} \Sigma_{0}^{\pi}+\sigma^{2}}$. Hence, with the values of the coefficients in equation (21) given as above, the functional form proposed for $x_{0}$ is consistent with agents' expectations and is therefore a Nash equilibrium of the problem.

\section{Proof of Corollary 1}

The projection theorem for normal distributions is used again to obtain the variance of the target level of inflation conditional on the information contained in the signal $x_{0}+\mu_{0} \cdot{ }^{21}$ Calling $I_{0}=x_{0}+\mu_{0}$ as before,

$$
\Sigma_{1}^{\pi} \equiv \operatorname{Var}\left[\bar{\pi} \mid I_{0}\right]=\Sigma_{0}^{\pi}-\Sigma_{\bar{\pi}, I_{0}} \Sigma_{I_{0}, I_{0}}^{-1} \Sigma_{I_{0}, \bar{\pi}}
$$

where $\Sigma_{a, b}=\operatorname{Cov}(a, b)$ for any random variables $a$ and $b$. Given equation (14), it is easy to see that

$$
\begin{aligned}
\Sigma_{\bar{\pi}, I_{0}} & =\Sigma_{I_{0}, \bar{\pi}}=p_{i} \Sigma_{0}^{\pi}, \\
\Sigma_{I_{0}, I_{0}} & =p_{i}^{2} \Sigma_{0}^{\pi}+\sigma^{2} .
\end{aligned}
$$

Therefore,

$$
\Sigma_{1}^{\pi}=\Sigma_{0}^{\pi}-\frac{p_{i}^{2} \Sigma_{0}^{\pi 2}}{p_{i}^{2} \Sigma_{0}^{\pi}+\sigma^{2}}=\left(1-\frac{p_{i}^{2} \Sigma_{0}^{\pi}}{p_{i}^{2} \Sigma_{0}^{\pi}+\sigma^{2}}\right) \Sigma_{0}^{\pi}
$$

\footnotetext{
${ }^{21}$ About variances, the theorem states that, given two jointly normally distributed random variables A and $B$ such that $\left[\begin{array}{l}A \\ B\end{array}\right] \sim N\left(\left[\begin{array}{l}\bar{A} \\ \bar{B}\end{array}\right],\left[\begin{array}{cc}\Sigma_{A A} & \Sigma_{A B} \\ \Sigma_{B A} & \Sigma_{B B}\end{array}\right]\right)$, the distribution of $A$ conditional on $B=b$ is also normal with variance $\operatorname{Var}[A \mid b]=\Sigma_{A A}-\Sigma_{A B} \Sigma_{B B}^{-1} \Sigma_{A B}$. See Granger and Newbold (1986), p. 298-299.
} 
Using the definition $\lambda_{i}=\frac{p_{s} \Sigma_{0}^{\pi}}{p_{s}^{2} \Sigma_{0}^{\pi}+\sigma^{2}}$ established in proposition 1 , the above expression can be rewritten as

$$
\Sigma_{1}^{\pi}=\left(1-\lambda_{i} p_{i}\right) \Sigma_{0}^{\pi}
$$

